\title{
Demand and Supply of Infrequent Payments as a Commitment Device: Evidence from Kenya*
}

\author{
Lorenzo Casaburi \\ Rocco Macchiavello \\ University of Zurich \\ London School of Economics
}

July 12, 2018

\begin{abstract}
Despite extensive evidence that preferences are often time-inconsistent, there is only scarce evidence of willingness to pay for commitment. Infrequent payments for frequently provided goods and services are a common feature of many markets and they may naturally provide commitment to save for lumpy expenses. Multiple experiments in the Kenyan dairy sector show that: i) farmers are willing to incur sizable costs to receive infrequent payments as a commitment device, ii) poor contract enforcement, however, limits competition among buyers in the supply of infrequent payments. We then present a model of demand and supply of infrequent payments and test its additional predictions.

Keywords: Commitment; Contract Enforcement; Saving Constraints; Agricultural Markets; Interlinked Transactions.

JEL Codes: O12, D90, O16, Q13.
\end{abstract}

\footnotetext{
* Lorenzo Casaburi, lorenzo.casaburi@econ.uzh.ch. Rocco Macchiavello, r.macchiavello@lse.ac.uk. Previous versions of the paper were circulated with the title "Firm and Market Response to Saving Constraints: Evidence from the Kenyan Dairy Industry." This project would have not been possible without the outstanding collaboration of Beatrice Agutu, Karen Ayabei, Joseph Gitiria, Patricia Gitonga, Greg Grothe, James Opot, Tim Dobermann, and the IPA Staff in Kenya. The project was approved by the IRBs of Maseno University (Kenya), Stanford University, and the University of Zurich. The experiments are registered in the American Economic Association's registry for randomized controlled trials (\#0000521). We thank Abhijit Banerjee, Jordi Blanes-i-Vidal, Moussa Blimpo, Gharad Bryan, David Dorn, Pascaline Dupas, Marcel Fafchamps, Andrew Foster, Patrick Francois, Maitreesh Ghatak, Douglas Gollin, Nir Jaimovich, Supreet Kaur, Asim Khwaja, Michael Kremer, Jacob Leshno, Dilip Mookherjee, Enrico Moretti, Ralph Ossa, Luigi Pistaferri, Dina Pomeranz, Gautam Rao, Imran Rasul, Debraj Ray, Orie Shelef, Tavneet Suri, Catherine Thomas, Chris Udry, Roberto Weber, Jack Willis, Daniel Xu, Noam Yuchtman, and participants at many seminars and conferences for their suggestions. We are particularly indebted to Tristan Reed, with whom this project was started, and to Land O' Lakes International Development and an anonymous donor for financial support.
} 


\section{Introduction}

Despite a great deal of evidence showing that individual preferences are often timeinconsistent, there is only scarce field evidence of willingness to incur sizable costs for commitment (Laibson, 2015; DellaVigna, 2017). In addition, most of the experimental evidence on demand for commitment relies on commitment products designed by behavioral economists, not on the analysis of commitment devices that exist in the market (Laibson, 2018).

This paper studies infrequent payments as a commitment device. Infrequent payments for frequently provided goods and services are a common feature of many goods and labor markets. They combine many small payments in one lump sum and thus may provide a natural commitment device to save for lumpy expenses. We show experimentally that Kenyan dairy farmers are willing to sell milk to a given buyer at substantially lower prices if they receive infrequent payments and that demand for commitment is an important driver of this preference. Additional experiments, however, show that many buyers lack the credibility to offer infrequent payments, thus limiting competition in the provision of this commitment product. Infrequent payments may provide financial commitment effectively, but poor contract enforcement increases the cost at which they are offered.

In the study setting, farmers supply milk daily to a large buyer (a cooperative) or to small, itinerant traders. The large buyer pays farmers once a month, traders pay mostly on a daily basis. In two "demand experiments", the large buyer privately offers farmers the option to choose between different payment frequencies for the subsequent month. In the first experiment, $86 \%$ of farmers pick monthly payments over daily payments even when the price for daily payments is $15 \%$ higher. In the second experiment, $93 \%$ of farmers turn down the option to choose every day whether to be paid that day or at the end of the month, thus preferring to "tie their hands" at the beginning of the month. The choice of this dominated strategy suggests that farmers value specifically the commitment that infrequent payments provide. Other potential benefits of infrequent payments, like lower transaction costs, cannot explain this choice. Additional lab-in-the-field experiments support this interpretation.

The price of this commitment device, and thus the welfare implications for farmers, 
depend on whether the market offers these services competitively or not (DellaVigna and Malmendier, 2004). We thus also study the supply side of infrequent payments (i.e., the demand side of the milk market). A puzzling aspect of our context is that, despite the existence of many buyers competing to buy milk, only the large buyer pays monthly. Unlike daily payments, monthly payments require the seller to trust that the buyer will pay the due balance at the end of the month. Two lab-in-the-field "supply experiments" —in which we endow farmers with additional milk and match them with traders from the same village - show that lack of credibility constrains traders' ability to offer monthly payments. When we exogenously make traders credible, farmers' willingness to sell to them for monthly payments (vs. daily payments) raises from $14 \%$ to $90 \%$. An additional experimental design shows that farmers are worried about traders' strategic default, not about traders' ability to hold money until the end of the month (i.e., not about traders also being saving constrained).

These results establish that producers have a strong demand for infrequent payments but that poor contract enforcement limits many buyers in their ability to supply them. They raise several questions: how do monthly payments facilitate commitment despite farmers also selling for daily payments to traders? And why can't small traders commit to offer monthly payments despite interacting with farmers on a repeated basis?

To shed light on these and other questions, we develop a model of demand and supply of infrequent payments. The framework features sophisticated $\beta \delta$ producers who can save to buy an indivisible good and can sell their output to buyers of heterogeneous credibility. Imperfect contract enforcement implies buyers can default on monthly payments and thus contracts must be self-enforcing. By preventing selves during the month from diverting the amount saved up to that point, monthly payments provide commitment and naturally arise in equilibrium. The commitment, however, is expensive: imperfect contract enforcement limits competition in the purchase prices for monthly payments. To be credible, a buyer must earn rents and thus the prices for delayed monthly payments are lower than for daily payments, i.e., the market features a negative interest rate. Furthermore, the most credible buyer sets a monthly price that is high enough to prevent entry of less credible competitors in the lucrative monthly payment market. A small-scale lab-in-the-field experiment confirms that, indeed, many traders would be willing to offer monthly payments at prevailing prices. A calibration of their incentive constraint, however, shows they would not be able to do so 
credibly, in line with the experimental findings. Finally, additional experimental evidence sheds light on how sale responses to price increases depend on buyer credibility and payment frequency.

Infrequent payments are common in many contexts, including other agricultural chains and labor markets. In the concluding section, we present original survey data from a tea contract farming scheme in Kenya; manufacturing sector workers in Myanmar; and seasonal workers in Rwanda. These surveys suggest a strong demand for infrequent payments, related to saving goals. More broadly, the historical shift toward (semi-)monthly wage payments (Engerman and Goldin, 1991) might have fostered durable purchase among the "middle class" employed in salaried jobs (Banerjee and Duflo, 2008; Gollin, 2002) 1

Demand for infrequent payments may be relevant in developed countries as well. For example, Thaler (1994) mentions that people like tax refunds and Adams et al. (2009) documents an increase in car purchases among low income people in the tax rebate season. Many countries instituted Thirteenth Salaries to provide more liquidity around Christmas expenses. While these institutions and patterns are consistent with a commitment purpose, other forces could also explain them (for instance, uncertainty (Highfill et al., 1998) or inertia (Jones, 2012) may explain tax overwithholding), and we are not aware of direct evidence on their commitment role. In addition, a literature on payday effects in rich countries implies that increasing the frequency of payments may enhance welfare by improving consumption smoothing (see, e.g., Stephens, 2003: Shapiro, 2005). Our results suggest that less frequent payments may on the other hand help for lumpy purchases and saving. From a policy angle, the demand for infrequent payments may thus have implications for cash transfer design in both poor and rich countries alike (Banerjee, 2016).2

There is by now abundant evidence that individual preferences are time-inconsistent and that commitment devices help in choices as diverse as saving, effort provision, and smoking

${ }_{1}^{1}$ Rutherford (2000) documents the importance of lump sums for the poor. Bauer et al. $(2012)$ argues that demand for lump sums may drive a correlation between present-biased preferences and demand for microcredit while Afzal et al. (2017) argues that it may explain simultaneous demand for saving and credit contracts. Our experimental evidence is consistent with poor households receiving negative interest rates on savings, for instance on deposits to money collectors (Collins et al. 2009). A large literature has focused on Roscas, which often pay negative returns and might also help overcome self-control problems (e.g., Gugerty, 2007). Roscas however also help deal with requests from friends and family members, provide insurance, have lower transaction costs and other benefits (Besley et al., 1995).

${ }^{2}$ In personal communication, Paul Niehaus reported to us that, in ongoing work, recipient of Give Directly transfers display strong preferences for infrequent disbursements. 
(see Duflo et al., 2011 on fertilizer use among maize farmers in Kenya and Bryan et al., 2010 for a review). While these papers are consistent with a demand for commitment, they do not provide evidence that subjects are willing to pay for it. Indeed, despite this substantial body of results, there is only scarce field evidence of willingness to incur sizable costs for commitment (Laibson, 2015, DellaVigna, 2017). For example, in the pioneering study by Ashraf et al. (2006), those subjects who opt for commitment (28\%) do not actually have to pay for it. In Augenblick et al. (2015), demand for commitment (on effort provision) is virtually zero when the cost is 25 cents. In Beshears et al. (2011), only about a quarter of the subjects are willing to incur a very small cost for the commitment plan. One exception is a recent paper by Schilbach (forthcoming) who, in a sample of Chennai rickshaw peddlers, finds that over a third prefer incentives for sobriety over unconditional payments, even when the unconditional payments were strictly higher $3^{3}$ Those subjects exhibit a demand for commitment on non-financial behavior. In contrast, we show a very large demand for financial commitment achieved through costly infrequent payments.

The paper thus contributes to the broader literature on saving constraints and saving products as well (see, e.g., Dupas and Robinson, 2013a; Karlan et al., 2014). Several recent papers focus on the mode of payment. i.e., cash vs. direct deposit (see, e.g., Brune et al. 2016 and Blumenstock et al., forthcoming). We instead focus on demand for and (constraints to) the supply of infrequent payments. Importantly, in our setting, farmers prefer infrequent payments even when the mode of payment between monthly and daily payments is the same (mobile money transfer), as shown in the above supply experiments. Our results suggest that, in an environment in which agents do have access to liquid forms of payment, infrequent payments help with lumpy expenses, a mechanism in line with evidence in Haushofer and Shapiro (2016) and Brune and Kerwin (2017).

Finally, since infrequent payments are de facto a saving commitment product, the transactions of milk and of saving services occur together, and thus are interlinked (Bardhan, 1991). A large literature has documented how credit constraints generate interlinkages between the exchange of goods, labor, and credit services.4 This paper contributes to this literature by

\footnotetext{
${ }^{3}$ The interested reader may refer to an updated and comprehensive survey table of the literature in Schilbach (forthcoming).

${ }^{4}$ Classic examples include interlinkages of credit with crop sales (Bell, 1988$)$, land tenancy (Braverman and Stiglitz, 1982) and labor provision (Bardhan, 1983, Mukherjee and Ray, 1995). Casaburi and Reed
} 
uncovering a previously unnoticed interlinkage between the transaction of goods and saving services, generated by saving constraints. The proposed mechanism is also distinct from standard trade credit (Petersen and Rajan, 1997, Breza and Liberman, 2017). Trade credit arises from a buyer's demand to reduce working capital requirements by delaying the timing of payments. In our mechanism, instead, saving-constrained sellers value delayed lump sums from credible buyers (or employers), as these help address self-control issues in spending habits. The paper thus complements Kaur et al. (2010) and Kaur et al. (2015) argument that the modern factory system might help address self-control problems in effort provision.

The rest of the paper proceeds as follows. Section 2 provides background information on the study setting. Section 3 presents two demand experiments, which show that farmers value infrequent payments as a commitment device. Section 4 presents two supply experiments, which show that buyer's credibility affects farmers' willingness to sell for monthly payments and that lack of credibility arises primarily from strategic default concerns. Section 5 presents a model of demand and supply of infrequent payments and tests its implications. Section 6 concludes, presenting survey evidence on the relevance of the mechanisms proposed here for other markets and discussing policy implications.

\section{Study Setting}

The dairy industry is the largest agricultural sector in Kenya, contributing to approximately $14 \%$ of agricultural GDP and 3.5\% of total GDP (Government of Kenya, 2012). Small-scale farmers, typically owning between one and three cows, are responsible for about $80 \%$ of the production (Wambugu et al. 2011). Our project takes places in Kiambu County, in Central Kenya. Two main types of buyers coexist in the region. The first is a large coop with about 2,000 members, one of the oldest in the industry. The coop collects milk at 24 collection centers, which are open at fixed hours every day in the morning and in the afternoon. The second is a large number of informal traders purchasing smaller quantities of milk. These are primarily small itinerant traders who deliver milk to the nearby towns (2017), Casaburi and Willis (forthcoming), Ghani and Reed (2017) and Macchiavello and Morjaria (2015a) offer recent empirical contributions. Imperfect contract enforcement lies at the heart of this literature. See, e.g. Macchiavello and Morjaria (2015b), Blouin and Macchiavello (2017) and, for a creative experimental approach, Bubb et al. (2016). More broadly, we build on the large literature on agricultural markets and institutions in Sub-Saharan Africa (Fafchamps, 2003). 
or local restaurants and to Nairobi (about one hour away). Both types of buyers sell milk to processors or to final consumers (local or in Nairobi). Approximately half of the dairy farmers in the coop's catchment area regularly sell milk to the coop (40\% in a listing of all dairy farmers that we conducted in six random villages).

Farmers milk cows twice a day (morning and afternoon). Since most farmers lack refrigerators, sales also typically occur twice a day. The coop and the traders differ in their frequency of payment. The coop pays farmers once a month, typically the first week of the subsequent month for deliveries, mostly through direct deposits into the farmer bank account. Traders pay mostly on a daily basis and sometimes weekly, in cash or through M-Pesa. Appendix B.2 provides more details on the buyers and on the differences across them.

Initial focus groups suggested that farmers value the coop's monthly payment as a saving device. We then conducted a survey with approximately 600 farmers that sell both to the coop and to traders (this serves as the baseline for the randomized controlled trial described in Section 5.2. $.95 \%$ of the respondents prefer that the coop pay at the end of month, rather than daily or weekly. Figure 1.Panel A shows that $82 \%$ of the farmers state that they set saving goals and that, among these farmers, $87 \%$ state they reach these goals most of the time, $71 \%$ that the coop helps reach these goals and $79 \%$ that they would be less likely to reach the saving goals if the coop paid weekly. The survey also suggested that credibility may be important in shaping a buyer's ability to supply infrequent payments. Figure 1.Panel B shows that farmers do not want the traders to provide less frequent payments: Only $18 \%$ of the farmers would like traders to pay less often. Moreover, when asked about the main reason for this preference, $68 \%$ of these respondents state that they are worried traders would default on the contract ("escape") if left with holding too much money from the farmers.

In summary, based on this survey descriptive evidence, we hypothesize that farmers may value infrequent payments and that credibility largely affects a buyer's ability to provide infrequent payments to farmers. The experiments presented in Section 3 and 4 test these hypotheses. 


\section{Producers' Demand for Infrequent Payments}

This section provides experimental evidence on whether and why farmers value infrequent payments. A first experiment shows that farmers selling to the coop are willing to accept a $15 \%$ lower price to receive monthly payments rather than daily payments. A second experiment shows that farmers value specifically the commitment offered by infrequent payments. Both experiments were conducted in Fall 2014. We also present additional lab-in-the-field and survey evidence.

\subsection{Demand Experiment 1: Do Producers Value Infrequent Pay- ments?}

Our main hypothesis is that farmers have a demand for coop's infrequent payments. If this is correct, farmers should be "willing to pay" for infrequent payments. The first experiment (DE1) aims at testing if farmers value infrequent payments:

Demand Experiment 1 (DE1): Farmers choose between two options concerning payments for their deliveries to the coop in the subsequent month: i) daily payments, at a 15\% higher price, or ii) monthly payments.

The experiment identifies farmers' demand for infrequent payments holding constant other features of the coop's demand (for example, other potential benefits, such as inputs, loans, demand reliability, or an intrinsic preferences for selling to the coop.) The coop management informed farmers that the coop was piloting new payment systems to offer a better service and increase deliveries from members. The coop offered farmers a price increase of 5 Kenyan shillings per liter (a 15\% increase) if they chose the daily payment. The meeting where information was provided and choices were made was held privately, in individual meeting locations. The experiment targeted a sample of 102 active members, randomly drawn from a list of farmers selling to the coop. 96 of these 102 farmers completed the experiment (94.1\%).

Farmers choosing monthly payments were paid through direct deposit. Farmers opting

for the daily payment were given the choice of being paid in cash or through mobile money transfers (it was not logistically feasible for the coop to arrange for daily direct deposits in the bank account). While the availability of these two options reduces differences in transaction costs between daily and monthly payments, any remaining difference may contribute to a 
preference for monthly payments. Therefore, Demand Experiment 1 does not aim to unbundle the multiple reasons why farmers may prefer infrequent payments. In the next section, we present the design of a second demand experiment, which isolates demand for commitment. Furthermore, we delve into the transaction cost issue in in Section 3.3 .

\subsection{Demand Experiment 2: Do Producers Value Commitment?}

Why would farmers value infrequent payments? A second demand experiment tests whether the demand for commitment is an important determinant of the demand for infrequent payments. We elicit whether farmers are willing to forgo flexibility to retain commitment. The second demand experiment is as follows:

Demand Experiment 2 (DE2): Farmers choose between two options concerning payment for their deliveries to the coop in the subsequent month: i) a "flexibility" option that, each day, allows farmers to choose whether to be paid that day or at the end of the month for milk delivered that day, or ii) monthly payments.

DE2 targeted another sample of 100 active members (drawn from the same population as DE1), reaching 95 of these. The coop offered these farmers a "flexible option" that allows them to choose every day whether they wanted to be paid daily or at the end of the month for their deliveries. Regardless of the option chosen (i.e., flexibility or monthly payments), farmers received an extra of KSh 5 per liter of milk delivered for that month. The farmer retained control every day on whether to exercise the option to be paid daily or not. As in $D E 1$, farmers exercising the flexible payment option could choose whether to be paid in cash or via mobile money transfer.

The main idea behind DE2 is that, through the flexible payment option, farmers can always replicate the cash flow profile of the monthly payment (if the farmer never exercises the daily payment option). Without the demand for commitment, the flexible payment then is strictly better if there is minimal uncertainty on daily cash needs or on traders' availability and prices (and weakly better otherwise) ${ }^{5}$ In particular, if the only barriers to savings were theft concerns, transaction costs, or family pressure, but not self-control problems, farmers

\footnotetext{
${ }^{5}$ In addition, the KSh 5 price increase is higher than the trader prices for about half of the farmers. For these farmers, even without uncertainty, the flexibility option thus still makes it harder to commit since offering cash at the point of sale induces a stronger temptation for the farmer.
} 
should choose the flexibility to get daily payments in any given day they may need them (e.g. if cash needs in any given day are particularly high). DE2 thus tests whether demand for commitment is a driver of the demand for infrequent payments. Table 1 Panel A presents summary statistics on the farmers who participated in the demand experiments.

\subsection{Demand Experiments: Results}

Farmers' Choices. In DE1, a large majority of farmers (86\%) is willing to forgo a $15 \%$ price increase to have monthly payments. The first bar in Figure 2 illustrates the results. Most farmers have high demand for infrequent payments from the coop. The second bar in Figure 2 summarizes the results of DE2. A very high share of farmers, 93\%, turns down the flexibility option. The combination of the two designs suggests that, while other reasons like transaction costs or safety concerns may also play a role, demand for commitment is a primary driver of demand for infrequent payments. ${ }^{6}$

Additional survey evidence supports the experimental results. We asked farmers the motivation for their choices. When eliciting the motivations, enumerators coded the respondent's answer without prompting options. Farmers who choose infrequent payments mention that they try to achieve saving targets (47\% in DE1, $42 \%$ in DE2) and that they do not trust themselves to handle the cash properly $(26 \%, 36 \%) .7$ As we describe in Appendix B.1, the experimental results are also consistent with descriptive evidence from survey data on: correlation between farmer characteristics and self-reported saving goals and habits (Appendix Table C.1); spending habits across income paid at different frequency (Appendix Figure C.1), and sorting across farmers into selling to the coop based on saving goals (Appendix Table C.2). Farmers' demand for infrequent payments is also consistent with the observed market price gap between monthly and daily payments: traders, who mostly pay daily, typically pay farmers a price per liter that is about $20 \%$ higher than the coop, who pays monthly (e.g.,

\footnotetext{
${ }^{6}$ Farmers selling to the coop typically make more than half of their sales to the coop. The fact that most farmers choose monthly payments implies that, in these experiments, we cannot study how sales to the coop respond to different frequencies of payments. In addition, the low variation in the choices of farmers in both $D E 1$ and DE2 implies that we do not find consistent correlation patterns between choices and farmer characteristics.

${ }^{7} 14 \%$ in $D E 1$ and $17 \%$ in DE2 mention that the spouse (typically the husband) wants to receive money on the coop account at the end of the month, suggesting that, in these cases, the wife, while managing the dairy business, does not have the authority to change the payment frequency.
} 
KSh 38 vs. KSh 31 in October 2014; this gap is stable across seasons and years). Obviously, many other differences between the coop and the itinerant traders may contribute to this gap, though 8

When considering these results, it is important to take into account that the demand experiments targeted only farmers selling to the coop. However, around the time of the demand experiments, we conducted a listing of all the dairy farmers in a random sample of six villages in the coop catchment area. In the listing, $40 \%$ of farmers sell to the coop (this is quite consistent with coop staff telling us that the coop sources milk from about half of the dairy farmers). Therefore, under the extremely conservative assumption that none of the other farmers would want infrequent payments, the share of farmers who choose infrequent payments at a $15 \%$ lower price would still be $0.4^{*} 0.86=0.34$. This is still very high relative to most of the existing literature on demand for commitment. It would be in line with Schilbach (forthcoming), who finds that about a third of study participants preferred incentives for sobriety over unconditional payments, even when the unconditional payments were strictly higher. Obviously, this is a very conservative lower bound since some non-coop farmers may also value infrequent payments. For instance, while there is a positive correlation between selling to the coop and having saving goals (Appendix Table C.2), 66\% of non-coop farmers still report having saving goals (vs. $87 \%$ of the coop ones).

The Distribution of Demand for Infrequent Payments. In the implementation of the two demand experiments, we were constrained by the coop's request to offer treatments at one price point only. Therefore, the experimental results are not informative of the distribution of farmers' demand for infrequent payments. For this purpose, we implemented an additional small lab-in-the-field experiment. The incentivized experiment elicited the farmer's reservation price for daily vs. monthly payment for an endowment of three liters of milk (approximately 30\% of a cow's daily production). If farmers choose the monthly payment option, they receive the payment for this milk through bank deposit at the end of the month, together with the payment for the rest of their milk sales to the coop. If they choose daily payment, they are paid immediately and have the option to receive the payment

\footnotetext{
${ }^{8}$ For instance, the coop provides training and veterinary services and its demand may be more reliable in peak production season. Few farmers buy inputs on credit from the coop. In the year of the study, the coop did not make second payments to farmers at the end of the year (i.e. no profit-sharing). Appendix B.2 provides more further details.
} 
in cash or mobile money.

Figure 3 shows that essentially no farmer chooses daily payments if the price is lower or equal to the one offered by the coop for monthly payments. The percentage of farmers choosing daily payment increases to $80 \%$ when the price gap increases to $10 \mathrm{KSh}$, i.e., onethird of the coop's monthly price. Although the results cannot be directly compared to those of the field demand experiments (where farmers had to make a decision for the entire month), they confirm farmers' willingness to incur costs to receive infrequent payments: the median willingness to pay for the end-of-month payments is between 13 and 23 percent of the milk price (approximately $60 \%$ of farmers accept a 13\% reduction and $40 \%$ a $23 \%$ reduction) ${ }^{9}$

Status Quo Bias, Costs of Thinking. A potential concern with the experimental designs is that, since the coop pays monthly, farmers' choices may be driven by status quo bias (see, e.g., Samuelson and Zeckhauser, 1988 and Kahneman et al., 1991). Several pieces of evidence mitigate this concern. First, farmers' motivations to choose monthly payments are mostly consistent with a demand for infrequent payments, arising from a demand for commitment. Second, the results of the additional lab-in-the-field experiments in Figure 3 show that many farmers do switch if given sufficient incentives to do so. Third, in Section 4. we present a supply experiment where the vast majority of farmers is willing to sell for monthly payments (vs. daily payments) to small traders when experimental manipulation makes these traders sufficiently credible. This is a stark departure from the status quo. Fourth, Casaburi and Macchiavello (2015) shows that farmers in the same population do respond to a change in the incentives provided by the coop, when this threatened stricter enforcement against side-selling. In sum, besides the direct evidence from the survey, there is abundant evidence that farmers in the sample are willing to switch between different payments frequencies (and, more generally, to change their supply behavior) if they are given incentives to do so.

Another possible explanation for the results of DE2 is that farmers may dislike the flexibility option because they want to avoid a daily "cost of thinking" (Ortoleva, 2013) or a "cost of keeping track" (Haushofer, 2015). Relatedly, farmers may worry that the coop may not be able to keep track of the payment preferences on a daily basis. However, if these were

\footnotetext{
${ }^{9}$ Since more farmers sell to the coop in the morning than in the afternoon, in this lab-in-the-field experiment we also tested whether willingness to pay for commitment was higher in the afternoon. Results, however, show no difference in the required price to accept daily payments across times of the day.
} 
the only motivations driving the results of DE2, as opposed to a demand for a commitment device, farmers should choose once and for all the daily payment over the monthly option in DE1. Similarly, even in DE2, farmers could simply inform the coop at the beginning of the month that they wanted to get paid daily for the rest of the month.

Why Such a Large Demand for Infrequent Payments? Our experimental results thus show that farmers have a strong demand for the commitment offered by infrequent payments. What could drive such a large demand? We hypothesize that infrequent payments have better commitment properties than other saving products. Farmers do have access to other saving tools including, possibly, commitment ones: $65 \%$ are members of saving groups and $75 \%$ save in a bank account. Further, commitment saving products, like the mobilebased M-Shwari Lock Saving Account, are available in Kenya (Bharadwaj et al., 2018) 10 So, why would the costly infrequent payment from the coop be a better commitment tool?

Infrequent payments may address demand for commitment in a natural and effective way for several reasons. First, money is withheld from the farmers until the end of the payment period. Time-inconsistent depositors who subscribe to a commitment saving account may never have money to deposit "right this minute", precisely because of their present bias. Infrequent payments, instead, commit farmers to have money taken from them until the end of the month, thus solving the problem. Second, a large, credible buyer (like the cooperative in our setting) may be able to overcome trust concerns - an argument we fully develop in the next section - and lack of knowledge of the financial provider (see Jack and Habyarimana, 2018). Third, the model in Section 5.1 highlights that a buyer can put pressure on the farmers to ensure deliveries, thus further helping them to achieve commitment. The punishment for side selling embedded in the relational contract with the coop may help the farmer overcome her temptations 11

The above points clarify that even the introduction of a new commitment saving account

\footnotetext{
${ }^{10}$ We note, however, that these commitment products often feature additional fees or reduced interest for early withdrawals, rather than a full limitation of access. As an example, the M-Shwari Lock Saving Account penalizes early withdrawals with a mere interest rate reduction of one percentage point. In addition, saving accounts with commitment features offered by commercial banks require an average initial deposit of $\$ 430$, an order of magnitude larger than the monthly revenues for most coop members (Ravi and Tyler, 2012 ).

${ }^{11}$ The coop sends warning letters to members who do not make enough sales or disqualifies these members from service provision (for instance, in February 2014, i.e., eight months before the demand experiments). In a few cases, it expels members who do not sell at all, though it tolerates sales to traders in the afternoon. Casaburi and Macchiavello (2015) provides additional details.
} 
with very harsh early withdrawal fees may not be enough to replace the infrequent payments as a saving device. Besides the illiquidity, the new saving product should have other important properties: automatically taking away milk earnings from the farmer at least until the end of the month; sufficient trust and knowledge toward the financial institution, "forced" deposits and punishment for non-deposits (akin to the relational contract argument described above). Understanding the impact on the provision of saving products on sale behavior (possibly with experimental variation in some of the above commitment features) is an interesting research question for future work.

Transaction Costs and Other-Control. Besides helping with self-control, infrequent payments may certainly have other benefits. We discuss two main potential benefits: reductions in transaction costs and reductions in other-control concerns.

In the demand experiments, farmers receive monthly payments through direct deposit in bank accounts and daily payments in cash or through mobile money. As discussed in Section 3.1, the differences in transaction costs across different modes of payments may in principle drive the results of $D E 1$. For instance, farmers may prefer direct deposit to mobile money transfers because mobile money has withdrawal fees (however, except for very small transactions, this fee is smaller than the price difference of DE1). Similarly, farmers may prefer direct deposit to the bank over cash because of safety concerns or because of the transaction costs (e.g. travel time) they would face when depositing daily payments in the bank account.12

Two considerations, however, suggest that differences in transaction costs are unlikely to explain the large demand for monthly payments in our setting. First, in the Supply Experiments presented in Section 4, farmers receive both daily and monthly payments under the same mode of payment (i.e., mobile money transfers). As we will see, in these experiments, farmers still exhibit high demand for infrequent payments (if buyers are credible). Second, lower transaction costs alone are unlikely to explain results in DE2. If the only difference between monthly payments and daily payments were transaction costs (rather than commit-

\footnotetext{
${ }^{12} \mathrm{~A}$ recent empirical literature documents how the mode of payment (i.e., cash vs. direct deposit) affects saving and spending. See, e.g., Brune et al. (2016), Brune et al. (2017), Somville and Vandewalle (forthcoming), Blumenstock et al. (forthcoming). Among others, Dupas and Robinson (2013a), Dupas and Robinson (2013b), Prina (2015), Kast and Pomeranz (2014), and Callen et al. (2016) study the impact of saving products in developing countries.
} 
ment concerns), a farmer should always opt to retain the flexibility to choose daily payments in any given day in which the marginal utility from daily consumption is larger than the difference in transaction costs. To summarize, while we acknowledge that lower transaction costs may be an additional benefit of infrequent payments, our experimental designs, results, and qualitative evidence strongly suggest they are not a main driver of the strong preference for infrequent payments in our setting.

Infrequent payments may in principle also help solve other-control problems. For instance, they may help hide money from other household members or from family and friends. However, because information on the flexibility option is private, results in DE2 capture demand for commitment arising from self-control problems. If farmers were solely concerned about pressure from their family or peers, they could privately pick the flexibility option and exert it only if the marginal utility from consumption in a given day is particularly high, in particular higher than the "sharing tax." Furthermore, the flexibility treatment did not constrain who delivered milk: the household could still send a family member or worker to deliver milk (this happens in about $30 \%$ of the cases), but instruct the milk clerk to disburse cash only following a request from the household, not from the milk delivery person. In addition, the farmers' motivations to choose monthly payments in the demand experiments point at a rather limited role for other-control problems as a source of demand for infrequent payments. At baseline, approximately $30 \%$ of farmers report to have been approached by others for financial help in the previous three months. The timing of these requests is not correlated with that of coop's payment. Concerns over workers handling cash do not seem to be important either: only $1.5 \%$ of farmers mention they do not trust the person who would handle cash in daily payments as a reason to choose monthly payments.

\section{Buyers' Supply of Infrequent Payments}

Farmers are willing to incur sizable costs to receive infrequent payments. The welfare consequences of such demand depend on whether this commitment device is competitively supplied or not (DellaVigna and Malmendier, 2004). Survey evidence shows that, while the large buyer pays monthly, essentially all the small traders pay daily. There are potentially many reasons why this happens. For instance, traders might be unable to offer infrequent 
payments if they are also saving constrained. Or farmers may have preferences for infrequent payments that are specific to the cooperative, e.g., a desire to help the coop by providing trade credit. We hypothesize that a key reason is that traders cannot supply infrequent payments due to their limited credibility. This section presents evidence from two lab-in-thefield experiments we conducted in Summer 2017 to test this hypothesis and distinguish it from competing explanations. The evidence shows that, under poor contract enforcement, a trader's credibility matters for his ability to offer infrequent payments: farmers are not willing to accept monthly payments from small traders because they are concerned traders would default on the amount due at the end of the month.

\subsection{Supply Experiment 1: Does Buyer Credibility Matter?}

The first experimental design is as follows:

Supply Experiment 1 (SE1): Farmers sell milk to a trader they know and choose how to split these sales between daily and monthly payments under two credibility treatments for the monthly payments. In the "guaranteed" treatment $(\boldsymbol{G})$, the experimenter guarantees the monthly payment to the farmer by deducting it from the trader payment and paying the farmer directly. In the "non-guaranteed" treatment (NG), the trader decides whether to pay the farmer at the end of the month or default. Daily payments are guaranteed in both treatments.

To test whether credibility matters, the first experiment varies the credibility of the trader when offering monthly payments (credibility is not a concern in daily payments). We then test whether farmers are relatively more willing to sell the same milk to the same trader under infrequent payments when the trader is more credible. We conduct lab-in-the-field experiments with farmers and traders that know each other, as described below. It is obviously possible that farmers do not have complete trust in the experimenter, either. This would make it harder to detect differences between treatments $G$ and $N G$. To check robustness of our findings to market conditions (and, as we discuss in Section 5.2 , to understand implications for sale responses to price increases), each farmer plays each pair of credibility treatments at three different price levels for the monthly payments (KSh 40, 50, or 60), while 
keeping the daily price at KSh 40, for a total of six games ${ }^{13}$

\subsection{Supply Experiment 2: Why Does Buyer Credibility Matter?}

Why may farmers not trust traders with monthly payments? A second supply experiment aims at distinguishing between two explanations. A possibility is that farmers believe that, in the absence of a payment guarantee mechanism, the trader would simply decide to keep the money and default at the end of the month. Another possibility is that farmers instead believe that the trader is also saving constrained and would default simply because he is not able to hold the due balance until the end of the month.

The second supply experiment tests whether trader's saving constraints alone matter in shaping the farmer's sale decisions:

Supply Experiment 2 (SE2): Farmers choose whether to sell to the trader for nonguaranteed monthly payments or for daily payments under two treatments concerning the traders' monthly non-guaranteed payments. In the standard non-guaranteed (NG) treatment, traders receive their payments daily and are thus potentially saving constrained. In the "no trader's saving constraints" non-guaranteed treatment $\left(\boldsymbol{N} \boldsymbol{G}_{n c}\right)$, traders receive their payments for the entire month at the end of the month. The farmer is informed about the trader's payment mode before he decides whether to sell for monthly or daily payments.

Therefore, in a seventh game, which otherwise is identical to the game with non-guaranteed monthly payment at price $50 \mathrm{KSh}$, the experimenter pays the trader for the entire month at the end of the month. This ensures the trader would have enough cash to pay the farmer, if he wished so. The farmer is informed about this. If the farmer believes that traders' saving constraints prevent him from paying at the end of the month, monthly sales in this last game should be larger than in the corresponding non-guaranteed treatment. If, instead, the farmer is concerned that the trader strategically defaults on due payments, relaxing the trader's saving constraint should not affect farmers' split between daily and monthly payments.

Implementing the Lab-in-the-Field Experiments. We list sixty farmers in four villages within the catchment area of the cooperative. We ask farmers to list milk traders

\footnotetext{
${ }^{13}$ In the supply experiments, monthly prices are (weakly) higher than daily ones. This choice takes into account that farmers must also trust the experimenters and that the choice is over additional milk, i.e., after farmers might have already met their demand for monthly payments by selling to the coop.
} 
they are familiar with and that operate in the same village. We then contact traders and verify they do know the farmers that listed them. Of the sixty targeted farmers, fifty-five came to the experimental sessions (all the traders confirmed their availability). Table1 1 Panel B presents summary statistics on the farmers who participated to the supply experiments.

Each farmer plays once each of the seven games in random order. In each game, the farmer is endowed with three liters of milk per day (approximately equal to the amount produced by a cow in the afternoon) for thirty days (i.e., 90 liters over thirty days). The farmer must sell this milk to the trader she is matched with. The farmer decides, once and for the entire month, how to split her daily endowment of milk between two forms of payments from the trader: daily and monthly.

Payments occur as it follows. The experimenter pays the trader a "trader price," which is constant across games at KSh 60 per liter. The farmer receives a "farmer price" which varies across games as described above. For all daily payments and for monthly payments in the guaranteed $(G)$ treatment, the experimenter pays the farmer by deducting the corresponding amount from the trader payment. For monthly payments in the non-guaranteed treatments ( $N G$ and $N G_{n c}$ ), the trader pays the farmer (or defaults). All payments, regardless of whether they are daily or monthly, occur via mobile money transfer, thereby removing differences in the mode of payment across payment frequencies. Farmers are paid daily or the end of the month according to their choices. Traders are paid daily, except in the "no trader's saving constraint" $\left(N G_{n c}\right)$ treatment, where they are paid at the end of the month. At the end of the experimental session, one of the seven games is randomly drawn and payment proceeds according to the outcomes of that game over the course of the ensuing month.

Unlike the demand experiments, which are conducted as field experiments, the supply experiments are lab-in-the-field experiments. In this controlled environment, we can shock traders' credibility (SE1) and cash availability for monthly payments (SE2) for specific transactions (i.e., "within" farmers). Implementing such a design as a field experiment would be significantly more challenging, if not altogether impossible ${ }^{14}$ Therefore, we pay particular

\footnotetext{
${ }^{14}$ First, we would need to vary treatments across traders, not across transactions within farmer-trader pairs. This would require interacting over a prolonged period of time with a much larger number of itinerant and unlicensed traders, a task notoriously difficult. Second, it would also require monitoring daily transactions between traders and farmers (and the form of payments) in an informal setting. Third, it would require persuading traders to participate and accept a lower amount of money to deduct the farmer's price in the treatment $G$. Finally, the coop, which is also the main partner in our study, did not endorse fieldwork that
} 
attention in designing lab-in-the-field experiments that closely mimic actual transactions. First, we play the games with actual farmers and traders that are accustomed to transact milk under conditions similar to those in the games. Second, we make sure to match farmers and traders that operate in the same villages and know each other. This guarantees that the farmer's choice in the one-shot interaction in the lab captures real-life perceptions about the credibility of traders she could actually sell to. Third, farmers make high-stake choices, concerning an endowment of milk that amounts to a sizable portion of their real milk sales.

\subsection{Supply Experiments: Results}

Trader's Credibility and Farmer Choices. Figure 4 presents the results. For each of the seven games, we show: i) the proportion of farmers who sell at least some milk for monthly payments (Panel A); ii) the average liters sold for monthly payments (Panel B). Consistent with the field evidence, when monthly payments are not guaranteed, very few farmers opt for monthly payments. The fraction of farmers selling a positive amount of milk for monthly sales raises from 0.14 in the non-guaranteed treatments to 0.9 in the guaranteed ones. Similarly, the average amount sold for monthly payments increases from 0.34 liters (out of an endowment of three liters) in the non-guaranteed treatments to approximately 2.6 liters when the monthly payment is guaranteed.

Table 2 reports estimates from regressions with farmer fixed effects. Columns (1)-(3) compare guaranteed and non-guaranteed treatments at each price point, while Column (4) reports results pooling the six games together. The drop in monthly sales in the non-guaranteed treatment is very large, statistically significant, and holds at different price levels.

Column (6) in Table 2 explores whether traders' saving constraints drive farmers' choices. This is not the case (as confirmed by comparing the fourth and fifth bar in Figure 4). In the $N G_{n c}$ treatment, paying traders at the end of the month-thus ensuring that they would have enough money to pay farmers at the end of the month - does not significantly change farmers' choices on either the extensive or the intensive margin. The evidence therefore suggests that, when monthly payments are not guaranteed, farmers are primarily concerned about the possibility that the traders might strategically default, not about their ability to hold money.

would de facto match its members to competitor traders risking to further compromise members loyalty. 
Although not the primary goal of the supply experiments, the results also confirm farmers' strong preference for infrequent payments. Under the guaranteed treatment, farmers overwhelmingly choose monthly payments. The results hold across a range of prices, including equal price under daily and monthly payment. The findings of Section 3 thus hold even when the mode of payment is constant between daily and monthly payments (since both are paid through mobile money transfer) and when the choice of monthly payments implies departing from the status quo (since, when the experimental treatments make them credible, the vast majority of farmers sells for monthly payments to small traders, who usually pay daily).

Discussion. These results show that traders' credibility affects farmers' willingness to accept infrequent payments. This is consistent with the survey evidence described in Section 2 (see Figure 1. Panel B). Farmers appear to trust traders a lot less than the coop. While many reasons could account for this difference, we note that the two types of buyers differ in farmers' ability to carry out an (informal) punishment strategy in case of payment default. Traders are mostly small and itinerant buyers and are characterized by relatively high turnover. Our survey reveals that, even within a village, there is little agreement across farmers in the number and identity of traders operating in the village. As a result, there is little community enforcement available to coordinate punishment against delinquent traders: a trader can default on one farmer and then move to a different village where information about the default has not spread.

In contrast, the coop is a large and visible institution, buying regularly at fixed premises (i.e., the collection centers) and with a well-known headquarter. Our survey also shows that farmers routinely discuss about the coop's management and affairs. 15 Defaulting against even one farmer could trigger punishment from many farmers and be very costly for the coop.

Taken together, the results from the supply experiments support the hypothesis that, under poor contract enforcement, the possibility of strategic default severely limits a trader's ability to offer monthly payments. In another small-scale experiment, we also verify that,

\footnotetext{
${ }^{15}$ In March 2014, the cooperative issued a letter to some farmers to remind them of the statutory provision according to which members are supposed to sell all milk to the cooperative (Casaburi and Macchiavello, 2015). Although only $45 \%$ of the farmers in our sample received the letter, $23 \%$ report knowing about it from other farmers. The average respondent in the survey reports discussing issues related to coop pricing policies and management with 2.3 other members from the village (significantly higher than interactions about dairy practices (1.16)). Farmers who had not received the letter were more likely to report having knowledge of it if $i$ ) they report knowing a higher share of other villagers and $i i$ ) a higher share of farmers received the letter.
} 
if given the opportunity, there would be many traders willing to offer monthly payments at current prices. We play incentivized lab-in-the-field experiments with sixteen of the traders mentioned by the farmers in the above supply experiments. Traders choose whether they offer farmers daily or monthly payments and are guaranteed that the farmer will accept the transaction regardless of their choice. We set the monthly price to be paid to the farmers to be KSh 5 per liter lower than daily prices, thus lower than the difference in market prices. Still, a majority of traders $(55 \%)$ chooses to pay the farmers monthly.

\section{Implications of the Saving-Output Interlinkage}

The experiments presented so far establish producers' demand for infrequent payments and constraints in buyers' supply of infrequent payments. These results raise several questions. For instance, how do monthly payments facilitate commitment even if farmers can sell for daily payments to traders? May the relationship with the buyer further help farmers achieve commitment? And why can't small traders commit to offer monthly payments despite interacting with farmers on a repeated basis?

To shed light on these and other questions, we present a model of supply and demand of infrequent payments. While the model draws from the study setting, it aims at providing a more general framework to study infrequent payments as commitment devices. The model also derives implications of the interlinkage between savings and output transactions for producers' sale responses to price increases. Section 5.1 presents the model. Section 5.2 tests the implications of the model with several experimental designs and a calibration exercise.

\subsection{A Model of Demand and Supply of Infrequent Payments}

\subsubsection{Setup}

Producers. Consider a market with a unitary mass of homogeneous producers. Time is an infinite sequence of months, $m$. Each month is divided into three periods, $t=1,2,3$. Producers have quasi-hyperbolic preferences across periods, with $\beta<1$ and $\delta<1$. They are sophisticated about their time inconsistency. In each of periods $t=1,2$, producers are endowed with one unit of non-storable output (milk). Producers cannot borrow. They can 
save cash from one period to the next within the same month, earning interest rate $(1+r)=$ $1 /(\delta+\epsilon)$, with $\epsilon \rightarrow 0^{+}$. In periods $t=1,2$, producers derive utility $u(c)=c$ from consumption of a perfectly divisible good $c$ (whose price is normalized to one). Following Besley et al. (1993) and Anderson and Baland (2002), we introduce a demand for an indivisible good that is purchased and consumed in the last period, $t=3$. The indivisible good costs $D$ and gives utility $\Delta>D$. We assume producers can afford to buy the indivisible good if they save more than one period worth of sales. Producer's utility at the beginning of the month is thus given by $U=c_{1}+\beta \delta\left(c_{2}+\delta I \Delta\right)$, where $I$ is an indicator function equal to 1 if the producer purchases the indivisible good. The assumptions imply that producers always prefer to consume the divisible good in earlier periods and that they only save to purchase the indivisible good.

Buyers. There are $N+1$ buyers, indexed $i=0,1,2, \ldots, N$. We refer to buyer 0 as the large buyer and to buyers $i=1,2, \ldots, N$, with $N \geq 2$, as small buyers. Buyers maximize discounted profits at common discount factor $\delta$ by reselling producers' output at exogenous price $v$. Buyers compete on prices and on whether they pay producers in each period $t=1$ and $t=2$ (i.e., daily payments) or once at $t=3$ (i.e., infrequent payments). If multiple buyers pay at the same frequency, they compete à la Bertrand. If two or more buyers buy for daily payments, Bertrand competition ensures that the daily price per liter is equal to $v$.

Monthly payments are however subject to contractual hazard: at $t=3$, a buyer can renege on the promised payment. When doing so, he faces a default cost. Buyers differ in their default costs. Upon reneging on a promise made to a producer for payment at $t=3$, small buyer $i$ can move to an identical outside market. In the outside market the defaulting buyer is randomly matched with producers who might or might not know about his past cheating. Let $\gamma \leq 1$ be the per-period probability the defaulting buyer is matched with an unaware producer in the outside market. In contrast, the large buyer cannot move to the outside market and, therefore, $\gamma_{L}=0$.

For expositional simplicity, we proceed in two steps. First, we understand the demand for infrequent payments when they are perfectly enforced (i.e., defaults on monthly payments are not possible) and subject to a buyer zero-profit constraint. As a benchmark, we begin by considering a liquid saving technology and then allow the large buyer to offer infrequent payments and show how this helps producers to save. We then allow infrequent payments to be part of a relational contract with the buyer, who punishes the producer for not delivering 
on a regular basis. We show that this threat further helps producers save. Second, we turn to the supply of infrequent payments under imperfect contract enforcement. We allow any buyer to offer monthly payments subject to a credibility constraint (i.e., the buyer must be given incentives to pay at the end of the month if he has promised to do so). In this scenario, we derive equilibrium prices for both daily and monthly payments and establish the large buyer monopsonistic position on infrequent payments as an equilibrium outcome.16

\subsubsection{When and Why Do Infrequent Payments Help Save?}

A Liquid Saving Technology. As a starting point, consider the case of a producer who, in a given month, must save on her own using the liquid saving technology. For the producer to be able to save and buy the indivisible good, two constraints must be met. First, there is a participation constraint: the producer's self at $t=1$ must be willing to start the saving plan. Second, there is an incentive constraint: the producer's self at $t=2$ must be given incentives to complete the saving plan set up by the previous self. Let $s_{1}$ be the amount the producer saved in $t=1$. At $t=2$ the producer completes the plan by saving $\delta D$ and purchasing the indivisible good in $t=3$ rather than consuming her income and savings if $v-\left(\delta D-s_{1}\right)+\beta \delta \Delta \geq v+s_{1}$. Given this constraint, the producer's self at $t=1$ starts the plan if she is patient enough. These constraints are both met if $\beta$ is greater than some threshold $\beta \geq \beta_{1}$.

Infrequent Payments as Commitment Saving. Consider now the case in which the producer can sell for infrequent payments that pay at $t=3$. When this is the case, the producer's self at $t=2$ cannot consume the savings passed on by her previous self and, therefore, is less tempted to abandon the saving plan. The incentive constraint is now given by $v-\delta\left(D-v x_{1} / \delta^{2}\right)+\beta \delta \Delta \geq v$, where $x_{1}$ is the amount self 1 sells for monthly payments. Given the now more relaxed incentive constraint, even a relatively less patient producer is willing to start the plan at $t=1$. That is, the indivisible good is purchased if $\beta \geq \beta_{2}$ with $\beta_{2}<\beta_{1}$. This is our first main result: infrequent payments allow to reduce temptations to over-consume at $t=2$ and thus act as a commitment saving product from the perspective of

\footnotetext{
${ }^{16}$ Appendix A provides proofs and algebra derivations and discusses a number of extensions to the baseline model. Considered extensions include, among others, producer heterogeneity, bundling of daily and infrequent payments, buyers' objective function and heterogeneity, producer access to credit, personal rules.
} 
producer's self at $t=1$.

Infrequent Payments with a Relational Buyer. The buyer can further help producers save by threatening to punish them if they fail to sell (and thus to save) on a regular basis. In doing so, the buyer introduces an additional reason to sell for illiquid payments in the current month: the value of continuing doing so in the future.

The intuition for the result comes again from the incentive constraint at $t=2$. Denote with $V^{\Delta}$ and $V^{0}$ the producer's continuation values when maintaining or leaving the relationship with the buyer respectively. If the producer sticks to the plan set up with the buyer she will be able to sell for infrequent payments (and thus save) in the future as well. If, instead, the producer fails to stick to the plan set up by the buyer, the buyer refuses to buy from the producer in the future. At $t=2$ the producer buys the indivisible good if $v\left(1-\delta\left(D / v-x_{1} / \delta^{2}\right)\right)+\beta \delta\left(\Delta+\delta V^{\Delta}\right) \geq v+\beta \delta\left(\delta V^{0}\right)$. If the producer is not able to save on her own (i.e., $\beta<\beta_{2}$ ), then the relationship with the buyer provides further disciplines to producer's self at $t=2$. The incentive constraint is even more relaxed than the one arising under infrequent payments alone since $V^{\Delta}>V^{0}$. There thus exists a threshold $\beta_{3}<\beta_{2}$ such that producers with $\beta \in\left[\beta_{3}, \beta_{2}\right)$ would be able to buy the indivisible good by selling for infrequent payments to a relational buyer, but not otherwise (in particular, even if they had access to infrequent payments without the relational contract).

We summarize this discussion with the following Proposition:

Proposition 1. Infrequent payments act as a commitment saving technology: for intermediate values of patience $\beta \in\left[\beta_{2}, \beta_{1}\right)$ the producer is able to save the desired amount with infrequent payments, but not otherwise. Furthermore, when infrequent payments are part of a relational contract with the buyer, the producer is able to save also if $\beta \in\left[\beta_{3}, \beta_{2}\right)$.

\subsubsection{Equilibrium Payment Frequency and Pricing under Imperfect Contract Enforcement}

Having understood the demand side of the market, i.e., the value of infrequent payments in helping producers with self-control problems, we now ask how they are supplied in a market with imperfect enforcement of such payments. In particular, can a relational contract like the one described above emerge in a market equilibrium? And would such a contract 
be competitively supplied when infrequent payments must also be self-enforcing? We thus consider the case in which both the large and the small buyers can offer and default on monthly payments. We characterize an equilibrium in which the large buyer sets prices such that small buyers are not able to credibly promise infrequent payments.

The Small Buyers. Consider a small buyer who offers monthly payments to a producer. The offer is credible if paying the promised amount at the end of the month and continuing the relationship with the producer gives the small buyer a higher discounted value than defaulting and then searching for another uninformed producer in the outside market. It can be shown that this is the case if the purchase price is less than $\delta^{3}(1-\gamma) v \equiv p^{S}$. Intuitively, when the share of uninformed producers, $\gamma$, is high, it is easier for the small buyer to find a new supplier and, therefore, the value of the relationship with the current producer is lower.

The Large Buyer. Consider now the large buyer offering monthly payments to the producers. In setting the price $p$ for infrequent payments, the buyer must take into account a number of constraints. First, the large buyer must be able to credibly offer infrequent payments. Recalling that $\gamma^{L}=0$, the purchase price under infrequent payments $p$ must be less than $\delta^{3} v \equiv p^{L}$. Second, the large buyer must prevent competition on infrequent payments from the small buyers. This can be achieved by setting a price $p$ that prevents small buyers from credibly offering monthly payments (i.e., the large buyer must offer a price $p>p^{S}$ ). Finally, the buyer must set a purchase price that is high enough to induce producers to enter the relational contract with infrequent payments, $p^{P}$. We know from the previous analysis that the relational contract can be beneficial to producers when $p=v$. Such a high price, however, cannot be credibly offered by the large buyer. In equilibrium, the large buyer sets a "limit price" $p^{*}$ that both induces producers to sell for infrequent payments and keep small traders out of the infrequent payment market. The described equilibrium thus exists if, at such limit price, the large buyer is credible, i.e., $p^{*}=\max \left\{p^{P}, p^{S}\right\} \leq p^{L}$. Since $p^{*}<v$, there exists a threshold $\beta_{4}$ such that producers with intermediate values of impatience $\beta \in\left[\beta_{3}, \beta_{4}\right)$ would sell through infrequent payments if they were competitively supplied under perfect enforcement but do not when such payments must be self-enforcing. We thus obtain the following proposition:

Proposition 2. When infrequent payments must be self-enforcing, the following equilibrium 
exists for intermediate values of patience $\beta \in\left(\beta_{4}, \beta_{1}\right)$ : i) the large buyer pays monthly at price $p^{*}<v$; ii) small buyers pay daily at price $v$; iii) producers purchase the indivisible good by selling to the large buyer under a relational contact with monthly payments and consume out of daily sales to smaller buyers.

Imperfect contract enforcement implies that, in equilibrium, the price for end-of-month payments, $p^{*}$, is lower than the price for daily payments, i.e., $p^{*}<v$. Infrequent payments are thus offered at negative interest rates, in stark contrast to standard trade credit logic in which delayed payments are charged positive interest rates.

Imperfect contract enforcement might also induce a barrier to entry in the market for monthly payments. In equilibrium, the large buyer ensures other buyers cannot credibly offer monthly payments to producers. Note, however, that under imperfect contract enforcement, even the large buyer must be credible when offering monthly payments (i.e., $p^{*} \leq \delta^{3} v \equiv p^{L}<$ $v$ ). This has implications for the case in which multiple large buyers (i.e., with $\gamma=0$ ) compete offering monthly payments. Competition would bid up the price for monthly payments only up to the maximum price at which these buyers remain credible, $p^{L}$. Since this is lower than $v$, monthly payments would still be provided at negative interest rates, even with competition among multiple large buyers.

\subsubsection{Implications}

The proposed equilibrium thus captures both experimental results from the previous sections: a demand for infrequent payments and their limited supply. The model also sheds light on how producers would respond to price increases. In particular, the model suggests that the sale response to an increase in price depends on $i$ ) whether the buyer is credible or not; and $i$ ) whether the price increase is offered only for monthly payments or not. Here, we informally discuss the logic of these additional implications. In the next section, we present additional evidence from experiments that exogenously induced buyers to offer large price increases.

First, consider a buyer who raises the price for monthly payments. This increase would raise the buyer's temptation to default and may make him no longer credible. Anticipating this, the producer may not increase, or actually decrease, her sales. In other words, under 
imperfect contract enforcement, sale responses to price increases would be smaller than for buyers who can commit to pay at each promised price.

Second, consider the case of the large buyer paying monthly. Consider an unanticipated and temporary (i.e., for only few days in a month) price increase in monthly payments, which raises the large buyer's price above $v$. The price increase now allows producers to achieve the desired saving amount with fewer sales. This dampens the sale response (and could, in principle, even generate a negative sale response). When the large buyer offers the same price increase with the additional option to pay daily for some of the deliveries, the supply response, however, will be larger. This is because producers will value the higher price for daily payments (and consumption) as well, which will induce a larger sale response. ${ }^{17}$

\subsection{Evidence on the Implications: Pricing and Sale Responses}

Pricing: Calibration of the Trader Incentive Constraint. Under the pricing equilibrium of the model, traders should not be able to credibly offer monthly payments at prevailing market prices. To explore this implication, we present a back-of-the-envelope calibration of the trader incentive constraint derived in the model. The exercise complements the results from the supply experiments presented in Section 4.

We slightly modify the trader's incentive constraint of the previous section to account for the fact that a month has 30 days. Given market prices $p^{M}$ and $p^{D}$ for monthly and daily payments respectively, the trader is not able to credibly offer monthly payments if:

$$
p^{\text {Monthly }} \geq \frac{1}{30} \delta(1-\gamma) \frac{1-\delta^{30}}{1-\delta} p^{\text {Daily }} .
$$

The trader cannot commit to monthly payments unless the purchase price for monthly payments is sufficiently below the price for daily payments. Intuitively, the highest price at which the trader can commit is increasing in $\delta$ (the trader's discount factor) and in $p^{\text {Daily }}$, and decreasing in the probability of finding a new farmer to match with after a default, $\gamma$.

Armed with this expression, we can ask whether at prevailing market prices, and for reasonable values of the parameters $\delta$ and $\gamma$, the trader is indeed able to commit to monthly

\footnotetext{
${ }^{17}$ The linear and discrete structure of the model implies extreme responses in which either nothing happens or the supply response goes to a corner. It is straightforward to extend the model (e.g., introducing producer's idiosyncratic preferences for each buyer) and obtain interior responses.
} 
payments. From the survey, we calibrate $p^{\text {Monthly }}=31$ and $p^{\text {Daily }}=38$ (the prevailing prices in October 2014). For each (annualized) discount factor, $\delta^{Y}$, we then compute the minimum level of $\gamma$ that would prevent traders from credibly committing. The range of considered discount factors $\delta$ spans plausible annual returns to capital for traders, from $5 \%$ to $233.33 \%$. Figure 5 presents the results. A trader defaults if $\gamma$ is above the frontier described by the dashed line. Across discount factors, the frontier for $\gamma$ lies between 0.14 and 0.18 . Therefore, at current market prices, traders would be able to commit to monthly payments only if information about previous defaults spread quickly across farmers (i.e., if $\gamma$ were very low). However, the survey evidence discussed in Section 4.3 suggests low levels of information sharing about traders, and thus limited opportunities for community punishment. ${ }^{18}$

Buyer Credibility and Sale Responses: Experimental Evidence. The experimental design for the supply experiments described in Section 4 allows us to test whether buyer's credibility affects sale responses to higher prices. Each farmer played the game at different prices. The monthly payments price varied between KSh 40, 50, and 60 (the daily payments price was always KSh 40). Column (5) in Table 2 provides support for the model's implication. In a regression of sale outcomes (binary or level), the interaction coefficients between the KSh 50 or KSh 60 price dummies and the non-guaranteed treatment are always negative (though they are significant at conventional levels only for the KSh 50 price dummy). This suggests that the sale response in the non-guaranteed monthly payments is flatter than the one for the guaranteed monthly payments.

Payment Frequency and Sale Responses: Experimental Evidence. An additional field experiment ("Price and Liquidity Experiment"), conducted in Fall 2014, tests whether sale responses to price increases depend on payment frequency. The prediction is relevant for farmers that sell to both the coop and to traders. We therefore focus on a sample of 398 farmers that regularly sell to the coop in the morning but not in the afternoon, and thus are likely to sell to traders in the afternoon. ${ }^{19}$ Farmers were randomly assigned to three groups: two treatments (150 in each) and one control group (98). In the first treatment,

\footnotetext{
${ }^{18}$ Appendix Figure C.2 explores robustness to various monthly prices and to traders' time-inconsistency.

${ }^{19}$ Appendix Figure C.3 shows that many farmers sell to the coop (almost) every day of the month and (almost) never in the afternoon. Three months before running the experiment, we conducted a baseline survey of 595 such farmers, which we use for the descriptive evidence presented in Figure 1. Appendix Figure C.4 provides an attempt to measure farmers' sales to traders.
} 
farmers were informed that for the subsequent three days they will receive a bonus of KSh 10 per liter (an increase of approximately 30\% relative to the baseline price) for afternoon deliveries. In the second treatment, in addition to the price increase, farmers were given the option to choose on a daily basis whether, for the deliveries in that day, they wanted to receive immediate payment or to retain the standard monthly payment. The farmers were given the opportunity to be paid daily for morning and/or afternoon deliveries for the three days according to their choice. The randomization was stratified by farmer location (four zones) and baseline delivery levels. ${ }^{20}$

Figure 6 summarizes the findings. The bonus treatment (the large price increase) has a positive but small impact on the afternoon deliveries. As predicted, the bonus+flexibility group has a larger impact. Table 3 confirms the results. We focus on kilograms delivered to the coop in the afternoon. Column (1) presents an OLS using only observations from the three days of the experiment. Column (2) shows results from a difference-in-differences model. Column (3) reports the estimation of a panel specification, with farmer fixed effects. The flexibility group displays an increase in afternoon deliveries of $0.24-0.29 \mathrm{~kg}$ per day, compared with a baseline level of zero. While, as hypothesized, the point estimate on this treatment is larger than the one on the bonus treatment $(0.13-0.15 \mathrm{~kg})$, the p-value of the difference in coefficients is 0.21-0.29, which induces some caution in interpreting the results ${ }^{21}$

Several factors could explain a quantitatively small impact. The difficulty in distinguishing sales to traders and own consumption made it difficult to target farmers that could respond to the intervention, yielding relatively small responses. Consistent with this, Appendix Table C.4 shows that the impact of the Bonus + Flexibility treatment is stronger for farmers that could respond: those with higher (morning) delivery level (Column 1), those less loyal to the coop (Column 2), and those with access to another trader (Column 3). Overall, while acknowledging the low precision of the estimates, the results provide suggestive evidence that the sale response to price increases depends on the frequency of payments.

\footnotetext{
${ }^{20}$ Appendix Table C.3 suggests that the randomization worked overall. The proportion of male respondents differs across the two treatment groups ( $\mathrm{p}$-value $=0.052$ ) and the proportion of farmers reporting access to traders differs across the flexibility and the control group (p-value $=0.079$ ). Around $6 \%$ of the treatment farmers could not be reached before the intervention (comparable across treatment groups).

${ }^{21} \mathrm{~A}$ binary indicator equal to one if the farmer sold any afternoon milk delivers similar results (Columns (4)-(6)). Columns (7)-(9) show results for morning deliveries. As expected, the point estimate for the bonus treatment is negative though, again, large standard errors prevent us from drawing any conclusion.
} 


\section{Conclusion}

The paper has provided experimental evidence on demand and supply of infrequent payments as a commitment device. Farmers are willing to incur a sizable cost to receive monthly payments and demand for commitment is an important driver of this preference. Due to imperfect contract enforcement, infrequent payments pay negative interest rates and might not be competitively supplied, thus raising the cost of accessing commitment for farmers. A theoretical model shows how supply and demand for infrequent payments interact in a market setting. The model also delivers additional predictions on pricing and sale responses to price increases in such a market, which we then test.

The Interlinkage in Other Markets. While this study is based on a specific setting, we conjecture its findings might be relevant for a broad class of markets featuring savingconstrained producers. In this final section, we discuss evidence from other settings. While the discussion is surely not sufficient to establish the relevance of the proposed mechanisms in other contexts, it nevertheless provides suggestive evidence that could motivate further research. First, evidence from other parts of the Kenyan dairy sector supports our results and interpretation. Studying dairy farmers in Nandi county, Geng et al. (2017) shows that farmers sell to buyers paying at different frequencies to balance saving and cash needs. In another location in Rift Valley, Kramer and Kunst (2017) replicates our first demand experiment, finding very similar results. In addition, $66 \%$ of dairy farmers report selling to the local cooperative because it can be trusted to save money for later, even if the coop pays a lower price than other buyers. These findings are also confirmed in focus groups with dairy farmers in several areas of Central Kenya (Morton et al., 2000). 22

Beyond the Kenyan dairy sector, Figure 7PPanel A presents survey evidence on producers' demand for infrequent payments in another agricultural value chain (the Kenyan tea sector) and in a labor market setting (workers in large garments factories in Myanmar). In both cases, the graph reports patterns remarkably consistent with those among our dairy farmers. In many agricultural value chains, large buyers source through infrequent payments. An example is provided by smallholder tea contract farmers, who pick leaves and sell them

\footnotetext{
${ }^{22}$ In many of these contexts, the large buyers pay at the end of the month a price lower than the price smaller traders pay daily. However, this is not true everywhere (Jack et al. 2016, Geng et al., 2017). Obviously, other differences across buyers can shape the specific price gap in each setting.
} 
multiple days per month (10-20 days depending on the timing of the season). In a survey of a random sample of 100 such farmers in Western Kenya, 81\% mention monthly payments as their preferred payment frequency and 95\% say monthly payments help save.

In many labor markets, infrequent wage payments from the employer may serve a similar commitment purpose than infrequent payments from buyers do in goods markets. The historical shift toward (semi-)monthly payments may have fostered durable purchase in the "middle class" of salaried workers (Banerjee and Duflo, 2008; Gollin, 2002). In a survey of 34 Myanmar garment factory workers (specifically, line supervisors), all the respondents mention monthly payments as their preferred payment frequency and $84 \%$ state that monthly payments help reach saving goals. Monthly payments may be particularly valuable in settings where important expenses (e.g., rent, bills) come on a monthly basis. Clark (1994) argued that the monitoring associated with the factory system helped workers deal with self-control in effort provision (Kaur et al., 2015 provides experimental evidence). Our results suggest that it can also help with self-control in saving and spending habits. Finally, a variety of labor markets institutions emerged to help workers save, e.g., in anticipation of high expenses during festivities. These include Employee Christmas Clubs, which are common in the United States, Eid Bonuses paid by government and large firms in Bangladesh ahead of Eid al-Fitr, and Thirteenth Salaries, which employers pay to workers in December in many countries around the world.

Our analysis also suggests that larger firms might be in a better position to offer infrequent payments credibly. In the tea setting, the survey shows that large buyers (cooperatives and large estates) pay monthly but smaller traders predominantly (68\%) pay daily. Figure 7 . Panel B provides further suggestive evidence. In a survey of 198 coffee mills in Rwanda, the graph documents a strong correlation between firm size and the likelihood the firm pays its (seasonal) workers on a monthly basis: $71 \%$ of the firms in the top quartile of the size distribution pay monthly but only $30 \%$ of the firms in the bottom quartile do.

To summarize, the mechanisms described in this paper may apply to several markets that feature saving-constrained producers (or workers). While we are aware the evidence in this section is just a first step that could be accounted for by different mechanisms, we nevertheless hope it will provide motivation for future research.

Policy Implications. Our analysis leads to a number of policy relevant considerations. 
First, producers' demand for infrequent payments suggest that these are an effective and natural commitment saving device, which is common in the real world. Policies promoting infrequent payments (for instance in labor contracts or cash transfers) may thus foster investment and purchase of durable goods. More work is needed to understand how to optimally structure payments to both help fund lumpy expenses and ensure consumption smoothing.

In addition, while infrequent payments may naturally target sophisticated individuals, attracting naive producers would require paying higher prices, as naive individuals do not recognize the commitment value of infrequent payments. There is no guarantee the market will extend infrequent payments to all those who need them 23 Consistent with this observation, a survey from a random sample of farmers in our study setting shows that farmers who do not regularly sell to the coop are less likely to achieve saving goals (Appendix Table C.2). Exploring the sorting of producers and workers with varying degrees of sophistication across different organizational forms is a further avenue for future research.

Second, our results emphasize the role of poor contract enforcement as a barrier to competition in the provision of infrequent payments. By increasing the number of buyers who can credibly commit to infrequent payments, better enforcement may have an impact similar to improving the terms of saving products (e.g., increasing the interest). This logic thus unveils a novel benefit of improving contract enforcement in goods and labor markets.

\footnotetext{
${ }^{23}$ See DellaVigna and Malmendier (2004) and Eliaz and Spiegler (2006) for a theoretical analysis of competition, sophistication and welfare, including the possibility that naive types end up with exploitative contracts.
} 


\section{References}

Abreu, Dilip. 1988. "On the theory of infinitely repeated games with discounting." Econometrica: Journal of the Econometric Society 383-396.

Adams, William, Liran Einav, and Jonathan Levin. 2009. "Liquidity constraints and imperfect information in subprime lending." American Economic Review, 99(1): 49-84.

Afzal, Uzma, Giovanna d'Adda, Marcel Fafchamps, Simon Quinn, and Farah Said. 2017. "Two sides of the same rupee? Comparing demand for microcredit and microsaving in a framed field experiment in rural Pakistan." The Economic Journal.

Anderson, Siwan, and Jean-Marie Baland. 2002. "The economics of roscas and intrahousehold resource allocation." Quarterly Journal of Economics 963-995.

Ashraf, Nava, Dean Karlan, and Wesley Yin. 2006. "Tying Odysseus to the mast: Evidence from a commitment savings product in the Philippines." The Quarterly Journal of Economics 635-672.

Augenblick, Ned, Muriel Niederle, and Charles Sprenger. 2015. "Working over time: Dynamic inconsistency in real effort tasks." The Quarterly Journal of Economics, 130(3): $1067-1115$.

Banerjee, Abhijit, and Sendhil Mullainathan. 2010. "The shape of temptation: Implications for the economic lives of the poor."

Banerjee, Abhijit V. 2016. "Policies for a better-fed world." Review of World Economics, 152(1): $3-17$.

Banerjee, Abhijit V, and Esther Duflo. 2008. "What is middle class about the middle classes around the world?" Journal of economic perspectives, 22(2): 3-28.

Bardhan, Pranab K. 1983. "Labor-tying in a poor agrarian economy: A theoretical and empirical analysis." The Quarterly Journal of Economics 501-514.

Bardhan, Pranab K. 1991. The economic theory of agrarian institutions.: Oxford University Press.

Bauer, Michal, Julie Chytilová, and Jonathan Morduch. 2012. "Behavioral foundations of microcredit: Experimental and survey evidence from rural India." American Economic Review, 102(2): 1118-39.

Bell, Clive. 1988. "Credit markets and interlinked transactions." In Handbook of Development Economics. eds. by Hollis Chenery, and T.N. Srinivasan, 1 of Handbook of Development Economics: Elsevier, , Chap. 16 763-830, URL: http://ideas.repec.org/h/eee/ devchp/1-16.html.

Bénabou, Roland, and Jean Tirole. 2004. "Willpower and personal rules." Journal of Political Economy, 112(4): 848-886.

Bernheim, B Douglas, Debraj Ray, and Şevin Yeltekin. 2015. "Poverty and SelfControl." Econometrica, 83(5): 1877-1911.

Beshears, John, James Choi, David Laibson, Brigitte Madrian, and Jung Sakong. 2011. "Self control and liquidity: How to design a commitment contract." 
Besley, Timothy et al. 1995. "Savings, credit and insurance." Handbook of development economics, 3 2123-2207.

Besley, Timothy, Stephen Coate, and Glenn Loury. 1993. "The economics of rotating savings and credit associations." The American Economic Review 792-810.

Bharadwaj, Prashant, William Jack, and Tavneet Suri. 2018. "Can Digital Loans Deliver? Take Up and Impacts of Digital Loans in Kenya."

Blouin, Arthur, and Rocco Macchiavello. 2017. "Strategic default in the international coffee market."

Blumenstock, Joshua, Michael Callen, and Tarek Ghani. forthcoming. "Why Do Defaults Affect Behavior? Experimental Evidence from Afghanistan." American Economic Review.

Braverman, Avishay, and Joseph E Stiglitz. 1982. "Sharecropping and the interlinking of agrarian markets." The American Economic Review 695-715.

Breza, Emily, and Andres Liberman. 2017. "Financial contracting and organizational form: Evidence from the regulation of trade credit." The Journal of Finance, 72(1): 291324.

Brune, Lasse, Xavier Gine, Jessica Goldberg, and Dean Yang. 2016. "Facilitating savings for agriculture: Field experimental evidence from Malawi." Economic Development and Cultural Change, 64(2): 187-220.

Brune, Lasse, Xavier Gine, Jessica Goldberg, and Dean Yang. 2017. "Savings defaults and payment delays for cash transfers: Field experimental evidence from Malawi." Journal of Development Economics, 1291 - 13.

Brune, Lasse, and Jason Kerwin. 2017. "Income Timing, Savings Constraints, and Temptation Spending: Evidence from a Randomized Field Experiment."

Bryan, Gharad, Dean Karlan, and Scott Nelson. 2010. "Commitment devices." Annu. Rev. Econ., 2(1): 671-698.

Bubb, Ryan, Supreet Kaur, and Sendhil Mullainathan. 2016. "Barriers to Contracting in Village Economies: A Test for Enforcement Constraints."

Callen, Michael, Suresh de Mel, Craig McIntosh, and Christopher Woodruff. 2016. "What Are the Headwaters of Formal Savings? Experimental Evidence from Sri Lanka."

Casaburi, Lorenzo, and Rocco Macchiavello. 2015. "Loyalty, Exit, and Enforcement: Evidence from a Kenya Dairy Cooperative." American Economic Review, 105(5): 286-90.

Casaburi, Lorenzo, and Tristan Reed. 2017. "Competition and Interlinkages in Agricultural Markets: An Experimental Approach."

Casaburi, Lorenzo, and Jack Willis. forthcoming. "Time vs. State in Insurance: Experimental Evidence from Contract Farming in Kenya." American Economic Review.

Clark, Gregory. 1994. "Factory discipline." The Journal of Economic History, 54(01): 128163. 
Collins, Daryl, Jonathan Morduch, Stuart Rutherford, and Orlanda Ruthven. 2009. Portfolios of the poor: how the world's poor live on \$2 a day.: Princeton University Press.

DellaVigna, Stefano. 2017. "Structural Behavioral Economics." Forthcoming in Handbook of Behavioral Economics, eds. David Laibson, Douglas Bernheim, and Stefano Della Vigna.

DellaVigna, Stefano, and Ulrike Malmendier. 2004. "Contract design and self-control: Theory and evidence." The Quarterly Journal of Economics, 119(2): 353-402.

Duflo, Esther, Michael Kremer, and Jonathan Robinson. 2011. "Nudging Farmers to Use Fertilizer: Theory and Experimental Evidence from Kenya." American Economic Review, 101(6): 2350-90, DOI: http://dx.doi.org/10.1257/aer.101.6.2350.

Dupas, Pascaline, and Jonathan Robinson. 2013a. "Savings Constraints and Microenterprise Development: Evidence from a Field Experiment in Kenya." American Economic Journal: Applied Economics, 5(1): 163-92.

Dupas, Pascaline, and Jonathan Robinson. 2013b. "Why Don't the Poor Save More? Evidence from Health Savings Experiments." American Economic Review, 103(4): 1138-71.

Eliaz, Kfir, and Ran Spiegler. 2006. "Contracting with diversely naive agents." The Review of Economic Studies, 73(3): 689-714.

Engerman, Stanley L, and Claudia Goldin. 1991. "Seasonality in Nineteenth Century Labor Markets." NBER Working Paper(h0020): .

Fafchamps, Marcel. 2003. Market institutions in sub-Saharan Africa: Theory and evidence.: MIT press.

Geng, Xin, Wendy Janssens, and Berber Kramer. 2017. "Liquid milk: Cash constraints and day-to-day intertemporal choice in financial diaries."

Ghani, Tarek, and Tristan Reed. 2017. "Relationships, risk and rents."

Gollin, Douglas. 2002. "Getting income shares right." Journal of political Economy, 110(2): 458-474.

Government of Kenya. 2012. "Economic Survey."

Gugerty, Mary Kay. 2007. "You can't save alone: Commitment in rotating savings and credit associations in Kenya." Economic Development and cultural change, 55(2): 251-282.

Haushofer, Johannes. 2015. "The cost of keeping track."Technical report, Working paper. Available at: https://www. princeton. edu/ joha/publications/Haushofer_CostofKeepingTrack_2015. pdf.[MIR-V].

Haushofer, Johannes, and Jeremy Shapiro. 2016. "The short-term impact of unconditional cash transfers to the poor: Experimental Evidence from Kenya." The Quarterly Journal of Economics, 131(4): 1973-2042.

Highfill, Jannett, Douglas Thorson, and William V Weber. 1998. "Tax overwithholding as a response to uncertainty." Public finance review, 26(4): 376-391. 
Jack, William, and James Habyarimana. 2018. "High Hopes: experimental evidence on saving and the transition to high school in Kenya."

Jack, William, Michael Kremer, Joost De Laat, and Tavneet Suri. 2016. "Borrowing Requirements, Credit Access, and Adverse Selection: Evidence from Kenya."Technical report, National Bureau of Economic Research.

Jones, Damon. 2012. "Inertia and overwithholding: explaining the prevalence of income tax refunds." American Economic Journal: Economic Policy, 4(1): 158-85.

Kahneman, Daniel, Jack L Knetsch, and Richard H Thaler. 1991. "Anomalies: The endowment effect, loss aversion, and status quo bias." The journal of economic perspectives, 5(1): 193-206.

Karlan, Dean, Aishwarya Lakshmi Ratan, and Jonathan Zinman. 2014. "Savings by and for the Poor: A Research Review and Agenda." Review of Income and Wealth, 60(1): $36-78$.

Kast, Felipe, and Dina Pomeranz. 2014. "Saving more to borrow less: Experimental evidence from access to formal savings accounts in Chile."Technical report, National Bureau of Economic Research.

Kaur, Supreet, Michael Kremer, and Sendhil Mullainathan. 2010. "Self-control and the development of work arrangements." The American Economic Review 624-628.

Kaur, Supreet, Michael Kremer, and Sendhil Mullainathan. 2015. "Self-control at work." Journal of Political Economy, 123(6): 1227-1277.

Kramer, Berber, and David Kunst. 2017. "Intertemporal choice and income regularity: Non-fungibility in a lab-in-the-field experiment."

Laibson, David. 1997. "Golden eggs and hyperbolic discounting." The Quarterly Journal of Economics 443-477.

Laibson, David. 2015. "Why don't present-biased agents make commitments?" The American economic review, 105(5): 267-272.

Laibson, David. 2018. "Private Paternalism, the Commitment Puzzle, and Model-Free Equilibrium." In American Economic Review-Papers $\&$ Proceedings.

Macchiavello, Rocco, and Ameet Morjaria. 2015a. "Competition and Relational Contracts: Evidence from Rwanda's Mills." Unpublished.

Macchiavello, Rocco, and Ameet Morjaria. 2015b. "The value of relationships: evidence from a supply shock to Kenyan rose exports." The American Economic Review, 105(9): 2911-2945.

Morton, John, Valentine Miheso et al. 2000. "Perceptions of livestock service delivery among smallholder dairy producers: case studies from Central Kenya." Livestock Research for Rural Development, 12(2): , p. 2000.

Mukherjee, Anindita, and Debraj Ray. 1995. "Labor tying." Journal of Development Economics, 47(2): 207-239. 
Ortoleva, Pietro. 2013. "The price of flexibility: Towards a theory of thinking aversion." Journal of Economic Theory, 148(3): 903-934.

Petersen, Mitchell A, and Raghuram G Rajan. 1997. "Trade credit: theories and evidence." Review of financial studies, 10(3): 661-691.

Prina, Silvia. 2015. "Banking the poor via savings accounts: Evidence from a field experiment." Journal of Development Economics, 115 16-31.

Ravi, Anjana, and Eric Tyler. 2012. "Savings for the Poor in Kenya." report by the Savings for the Poor Innovation and Knowledge Network (Washington: New American Foundation, May), 20.

Rutherford, Stuart. 2000. The poor and their money.: Oxford University Press New Delhi.

Samuelson, William, and Richard Zeckhauser. 1988. "Status quo bias in decision making." Journal of risk and uncertainty, 1(1): 7-59.

Schilbach, Frank. forthcoming. "Alcohol and Self-Control: A Field Experiment in India." American Economic Review.

Shapiro, Jesse M. 2005. "Is there a daily discount rate? Evidence from the food stamp nutrition cycle." Journal of public Economics, 89(2): 303-325.

Somville, Vincent, and Lore Vandewalle. forthcoming. "Saving by Default: Evidence from a Field Experiment in Rural India." American Economic Journal: Applied Economics.

Stephens, Melvin. 2003. "” 3rd of tha Month": Do Social Security Recipients Smooth Consumption Between Checks?" American Economic Review 406-422.

Strotz, Robert Henry. 1955. "Myopia and inconsistency in dynamic utility maximization." The Review of Economic Studies 165-180.

Thaler, Richard H. 1994. "Psychology and savings policies." The American Economic Review, 84(2): 186-192.

Wambugu, Stella, Lilian Kirimi, and Joseph Opiyo. 2011. "Productivity trends and performance of dairy farming in Kenya." Tegemeo Institute of Agricultural Policy and Development. 


\section{Figures}

Figure 1: Descriptive Evidence: Farmers, Traders, and Infrequent Payments

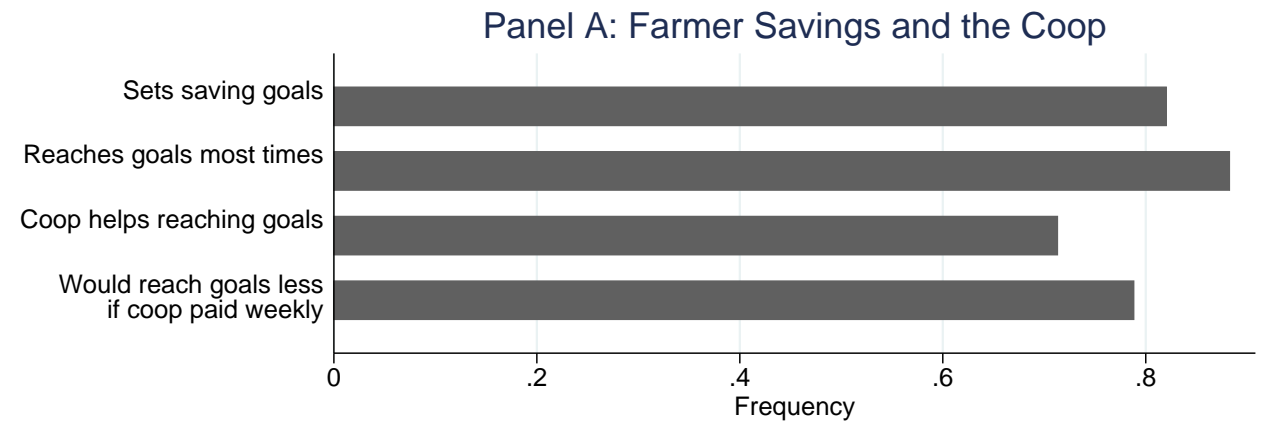

Panel B: Traders and Low Frequency Payments

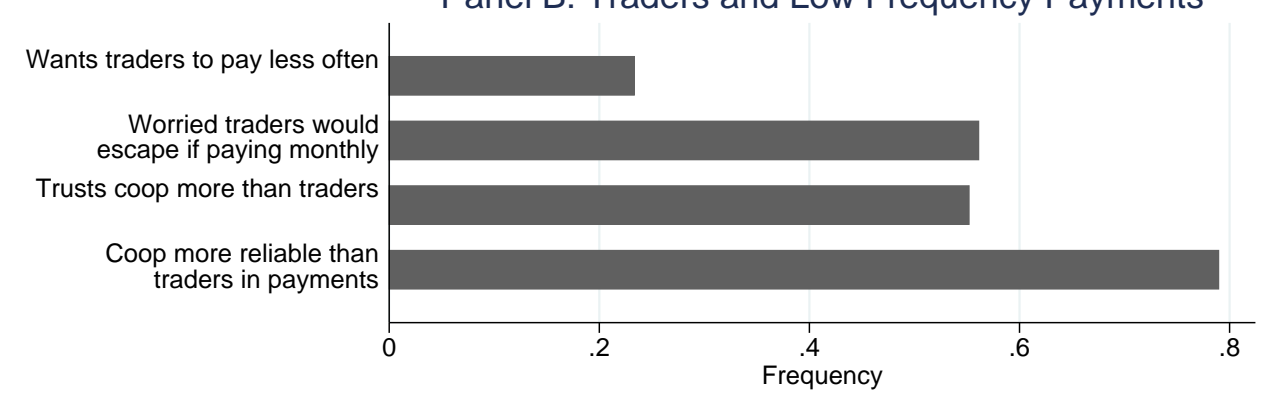

Notes: The figures presents descriptive statistics from the baseline survey ( $\mathrm{N}=596)$. Panel A presents summary statistics on farmer savings behavior and on the role of the coop in helping savings. All the variables are binary indicators and the horizontal bars display the frequency of farmers agreeing with the statement in the baseline survey. For the first variable, "Set saving goals", we use the entire baseline sample. For the other variables, we restrict the sample to those farmers who state they set saving goals. "Would reach goals less if coop paid weekly" takes value one if a farmer answers "less often than I do currently" to the question "If the coop paid every week, how often would you reach your saving goals?" Panel B presents summary statistics on farmer attitudes toward traders other than the coop. The binary indicators "Trusts coops more than traders" and "Coop more reliable than traders in payments" are equal to one if the trust score or the payment reliability score are strictly larger for the coop than for other buyers, respectively. In the survey, the variable Trust for either the coop and the buyer is measured on an index from 1 to 4 and the average difference between the two is 0.853 . 


\section{Figure 2: Demand Experiments: Farmers' Demand for Infrequent Payments}

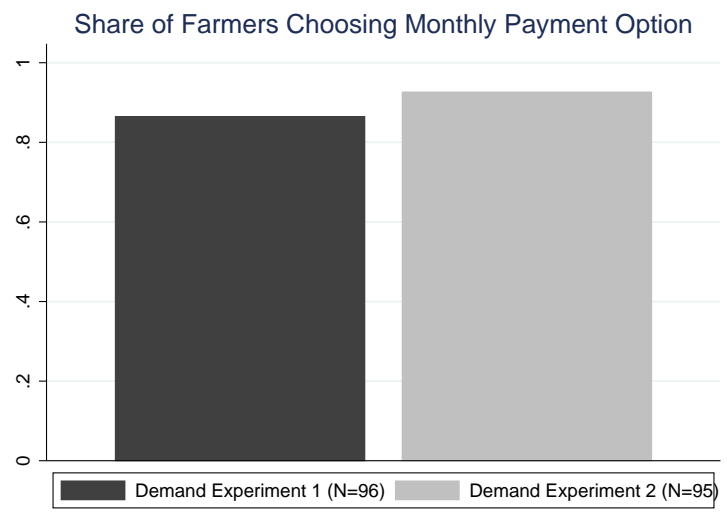

Notes: The figure presents results from the demand experiments described in Section 3 . The left bar focuses on the first demand experiment $(\boldsymbol{D E} 1)$. It reports the share of farmers who choose monthly payments over daily payments with a bonus of KSh 5 (from a baseline of KSh 31). The right bar focuses on the second demand experiment (DE2). It reports the share of farmers who chose monthly payments over the "flexibility" option, which would allow them to choose every day whether to be paid daily or monthly.

Figure 3: Demand Lab-in-the-Field Experiment

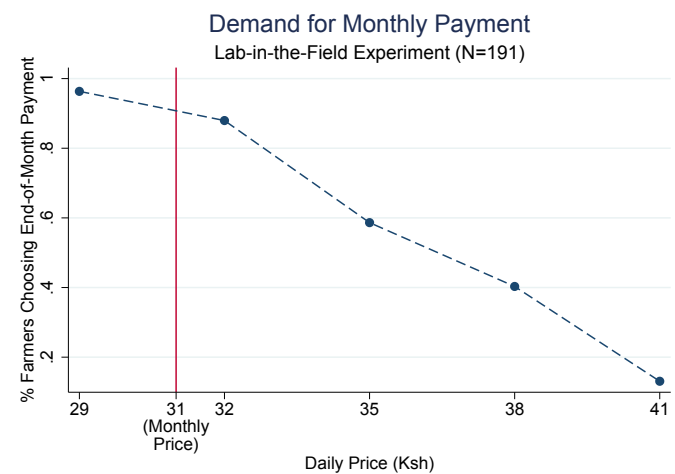

Notes: The figure presents results from the demand lab-in-the-field experiment described in Section 3.3 (Distribution of Demand for Infrequent Payments). This lab-in-the-field experiment followed a within-subject design: farmers decided whether to sell three liters of milk for monthly or daily payments at various prices per liter for the daily payment option. The y-axis reports the share of farmers who prefer the end-of-month payment at five price points. The vertical line represents the (constant) price per liter under the monthly payment. 
Figure 4: Supply Experiments: Trader Credibility and Monthly Sales

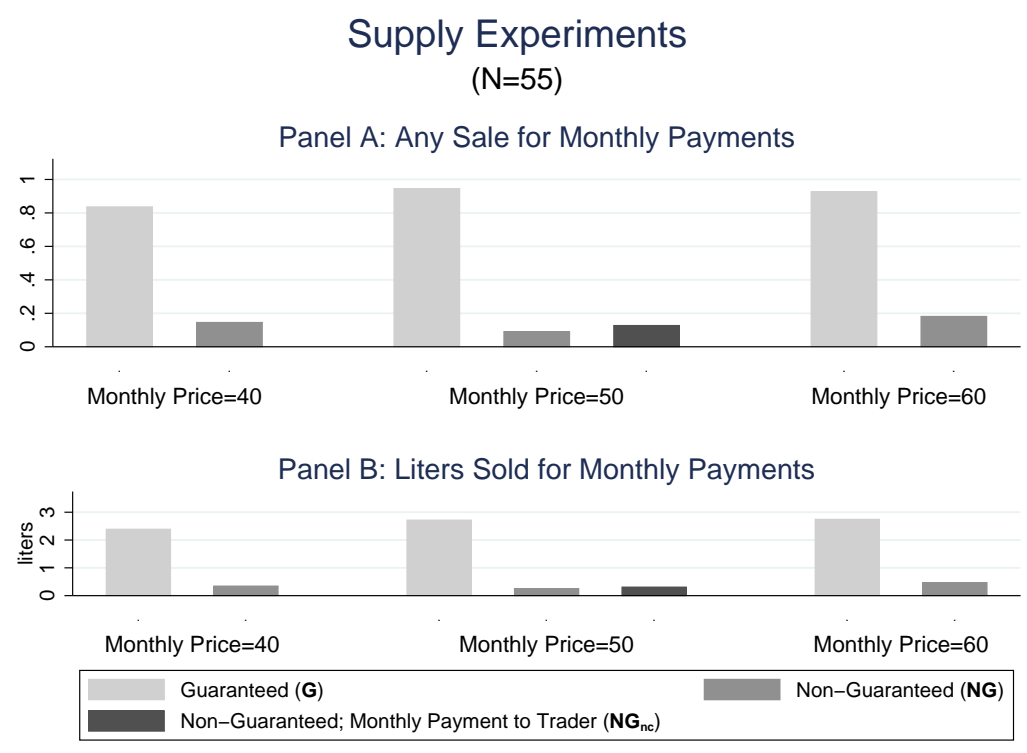

Notes: The figure presents the results from the supply experiments described in Section 4 Farmers played seven games in which they had to choose once and for all how much to sell for monthly vs. daily payments. In each game farmers were endowed with three liters per day for the duration of a month (i.e., 90 liters). Farmers played the games in random order. The price per liter for daily payments was close to prevailing market prices at the time of the experiment and fixed at KSh 40 per liter. The price of monthly payments varied across games: KSh 40,50,60. Section 4 describes the three treatments concerning monthly payments: guaranteed $(G)$, non-guaranteed $(N G)$ and non-guaranteed with monthly payment to the trader $\left(N G_{n c}\right)$. The $N G_{n c}$ treatment was played only with the monthly price at KSh 50 per liter. For each of the seven games, Panel A reports the proportion of farmers who sell a positive amount of milk for monthly payments and Panel B reports the average amount of daily liters sold for monthly payments out of the experimentally provided endowment. 


\section{Figure 5: Trader's Incentive Constraint Calibration}

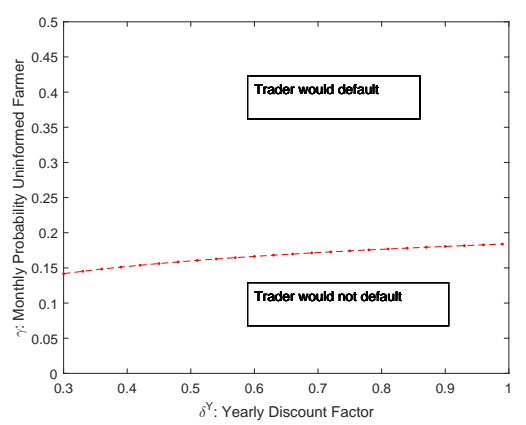

Notes: The figure shows pairs $\left(\delta^{Y}, \gamma\right)$ that satisfy the inequality of the trader incentive constraint of the empirical model (Equation 1) - where $\delta^{Y}$ is the annual discount factor and $\gamma$ is the likelihood a trader matches with an uninformed farmer after a default. Monthly price $p^{M}$ and daily price $p^{D}$ are calibrated based on prevailing market prices at KSh 31 and 38, respectively. A trader defaults if $\gamma$ is above the frontier described by the dashed line in the figure. The figure shows that unless farmers are implausibly well-informed about traders default, traders would not be able to commit to monthly payments. The result holds for a range of discount factors that imply annual interest rates spanning the plausible range of annual returns to capital to traders (from $5 \%$ to $233.33 \%$ in the figure). Appendix Figure C.2 shows robustness when varying monthly prices or allowing for trader time inconsistency.

Figure 6: Price and Liquidity Experiment

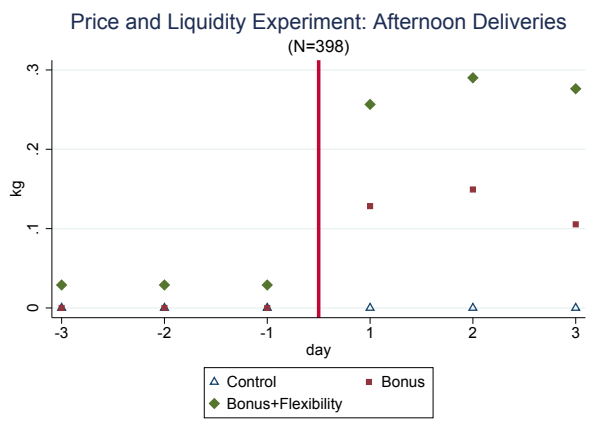

Notes: The figure presents the results of the Price and Flexibility randomized experiment described in Section 5.2 . The experiment targeted farmers selling to the coop in the morning but not in the afternoon at baseline. Farmers in the Bonus group received an increase in milk price of 10 Kenyan shillings for afternoon deliveries. Farmers in the Bonus +Flexibility group received the same price increase and the option to choose each day whether to be paid daily or at the end of the month. The y-axis reports average afternoon deliveries for the two treatment groups and the control group. Days 1 to 3 refer to the days of the experiment. Days -3 to -1 refer to the same calendar days of the month before the experiment. 
Figure 7: Survey Evidence from Other Settings
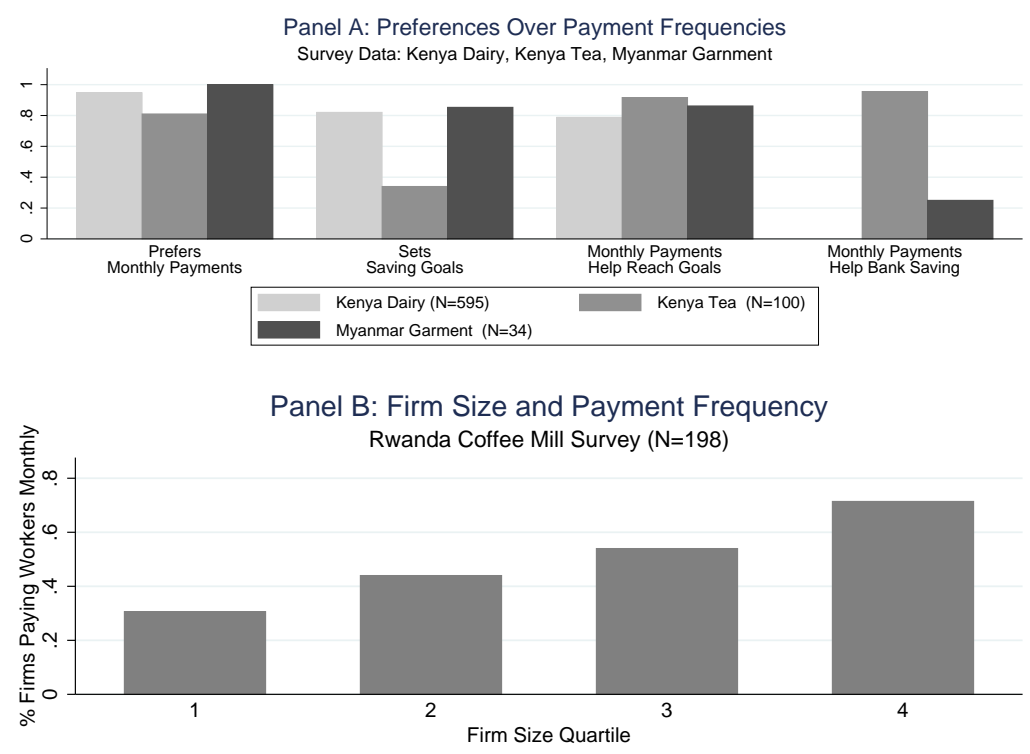

Notes: Panel A reports percentage of respondents agreeing with the four statements in three different surveys: dairy farmers in Kiambu, Central Kenya (left bar); tea growers in Kericho, Western Kenya (center bar); and line supervisors in garments factories in Yangon, Myanmar (right bar). The question "Do Monthly Payments Help Bank Saving" was not asked to dairy farmers in Kiambu. Panel B reports the percentage of coffee mills in Rwanda paying monthly wages (as opposed to biweekly, weekly and daily wages) to seasonal employees during the 2015 harvest season. The figure shows larger mills pay less frequently. We thank Ameet Morjaria for sharing the data from Rwanda. 


\section{Tables}

Table 1: Summary Statistics for Demand and Supply Experiments

\begin{tabular}{lcccc}
\hline \hline & \multicolumn{2}{c}{$\begin{array}{c}\text { Panel A: } \\
\text { Demand Experiments } \\
\end{array}$} & $\begin{array}{c}\text { Panel B: } \\
(\mathrm{N}=191)\end{array}$ & \multicolumn{2}{c}{$\begin{array}{c}\text { Supply Experiments } \\
\text { (N=55) }\end{array}$} \\
\hline Variable & Mean & Std. Dev. & Mean & Std. Dev. \\
Male respondent & 0.411 & 0.493 & 0.404 & 0.496 \\
Respondent age & 55.319 & 14.582 & 51.106 & 12.497 \\
Household size & 4.639 & 2.013 & 4.085 & 1.73 \\
Number of cows & 1.88 & 1.129 & 2.109 & 1.449 \\
Daily milk production (lt.) & 16.88 & 14.36 & 16.65 & 13.71 \\
Sets saving goals & 0.869 & 0.338 & 1 & 0 \\
Saves in saving groups & 0.652 & 0.478 & 0.638 & 0.486 \\
Saves in bank & 0.757 & 0.43 & 0.851 & 0.36 \\
Hires workers for dairy & 0.403 & 0.492 & 0.638 & 0.486 \\
Knows any other village buyer & 0.8 & 0.401 & 1 & 0 \\
\hline
\end{tabular}

Notes: The table presents summary statistics for the farmers targeted in the demand experiments presented in Section 3 and in the supply experiments presented in Section 4. In Panel B, the mean of "knows any other village buyer" is equal to 1 by construction, since we only targeted farmers who did business with at least another buyer in the village. 
Table 2: Supply Experiments

\begin{tabular}{|c|c|c|c|c|c|c|}
\hline \multirow[t]{2}{*}{ Monthly Price $(K S h)=$} & \multirow{2}{*}{$\begin{array}{l}40 \\
(1)\end{array}$} & \multirow{2}{*}{$\begin{array}{l}50 \\
(2)\end{array}$} & \multirow{2}{*}{$\begin{array}{l}60 \\
(3) \\
\end{array}$} & \multicolumn{2}{|c|}{$40,50,60$} & \multirow{2}{*}{$\begin{array}{l}50 \\
(6)\end{array}$} \\
\hline & & & & $(4)$ & $(5)$ & \\
\hline \multicolumn{7}{|l|}{ Panel A: Any Monthly Sale (dummy) } \\
\hline Non-Guaranteed & $\begin{array}{c}-0.691^{* * *} \\
{[0.063]}\end{array}$ & $\begin{array}{c}-0.855^{* * *} \\
{[0.048]}\end{array}$ & $\begin{array}{c}-0.745^{* * *} \\
{[0.059]}\end{array}$ & $\begin{array}{c}-0.764^{* * *} \\
{[0.030]}\end{array}$ & $\begin{array}{c}-0.691^{* * *} \\
{[0.052]}\end{array}$ & $\begin{array}{c}-0.855^{* * *} \\
{[0.046]}\end{array}$ \\
\hline Price $=50$ & & & & $\begin{array}{c}0.027 \\
{[0.037]}\end{array}$ & $\begin{array}{c}0.109^{* *} \\
{[0.052]}\end{array}$ & \\
\hline Price $=50 *$ Non Guaranteed & & & & & $\begin{array}{c}-0.164^{* *} \\
{[0.074]}\end{array}$ & \\
\hline Price $=60$ & & & & $\begin{array}{l}0.064^{*} \\
{[0.037]}\end{array}$ & $\begin{array}{l}0.091^{*} \\
{[0.052]}\end{array}$ & \\
\hline Price $=60 *$ Non Guaranteed & & & & & $\begin{array}{l}-0.055 \\
{[0.074]}\end{array}$ & \\
\hline Monthly Payment to Trader & & & & & & $\begin{array}{c}0.036 \\
{[0.046]} \\
\end{array}$ \\
\hline Mean Y Baseline Group & 0.836 & 0.945 & 0.927 & 0.903 & 0.903 & 0.145 \\
\hline Observations & 110 & 110 & 110 & 330 & 330 & 165 \\
\hline \multicolumn{7}{|l|}{ Panel B: Monthly Sales (liters) } \\
\hline Non-Guaranteed & $\begin{array}{c}-2.045^{* * *} \\
{[0.186]}\end{array}$ & $\begin{array}{c}-2.464^{* * *} \\
{[0.143]}\end{array}$ & $\begin{array}{c}-2.273^{* * *} \\
{[0.173]}\end{array}$ & $\begin{array}{c}-2.261^{* * *} \\
{[0.089]}\end{array}$ & $\begin{array}{c}-2.045^{* * *} \\
{[0.154]}\end{array}$ & $\begin{array}{c}-2.464^{* * *} \\
{[0.131]}\end{array}$ \\
\hline Price $=50$ & & & & $\begin{array}{c}0.118 \\
{[0.109]}\end{array}$ & $\begin{array}{c}0.327^{* *} \\
{[0.154]}\end{array}$ & \\
\hline Price $=50 *$ Non Guaranteed & & & & & $\begin{array}{c}-0.418^{*} \\
{[0.218]}\end{array}$ & \\
\hline Price $=60$ & & & & $\begin{array}{c}0.241^{* *} \\
{[0.109]}\end{array}$ & $\begin{array}{c}0.355^{* *} \\
{[0.154]}\end{array}$ & \\
\hline Price $=60 *$ Non Guaranteed & & & & & $\begin{array}{l}-0.227 \\
{[0.218]}\end{array}$ & \\
\hline Monthly Payment to Trader & & & & & & $\begin{array}{c}0.055 \\
{[0.131]} \\
\end{array}$ \\
\hline Mean Y Baseline Group & 2.391 & 2.718 & 2.745 & 2.618 & 2.618 & 0.345 \\
\hline Observations & 110 & 110 & 110 & 330 & 330 & 165 \\
\hline
\end{tabular}

Notes: The table presents the results from the supply experiments presented in Section 4 Farmers played seven games in which they had to choose, once and for all, how much to sell on monthly vs. daily payments, out of an endowment of three liters per day for the duration of a month (90 liters). Farmers played the games in random order. The price per liter for daily payments was close to prevailing market prices at the time of the experiment and fixed at KSh 40 per liter. The price of monthly payments varied across games: KSh 40, 50, 60. Section 4 describes the three treatments concerning monthly payments: guaranteed $(G)$, non-guaranteed $(N G)$ and non-guaranteed with monthly payment to the trader $\left(N G_{n c}\right)$. The dependent variable in Panel A is a dummy equal to one if a farmer sells a positive amount of milk for monthly payments and in Panel $\mathbf{B}$ is the amount of liters the farmer sells for monthly payments (out of a daily endowment of three liters). Columns (1), (2), and (3) report results for Supply Experiment 1, when the monthly price is equal to KSh 40,50 , and 60 , respectively. Column (4) pools the previous samples. Column (5) shows heterogeneity in the impact of price increases by guaranteed treatment (see discussion in Section 5.2). Column (6) presents the results of Supply Experiment 2, comparing monthly sales among the $G, N G$ and $N G_{n c}$ treatments (at KSh 50 for monthly payments). All specifications include farmer fixed effects. Standard errors are clustered by farmer. ${ }^{*} \mathrm{p}<0.1,{ }^{*} \mathrm{p}<0.05,{ }^{* * *} \mathrm{p}<0.01$. 
Table 3: Price and Liquidity Experiment

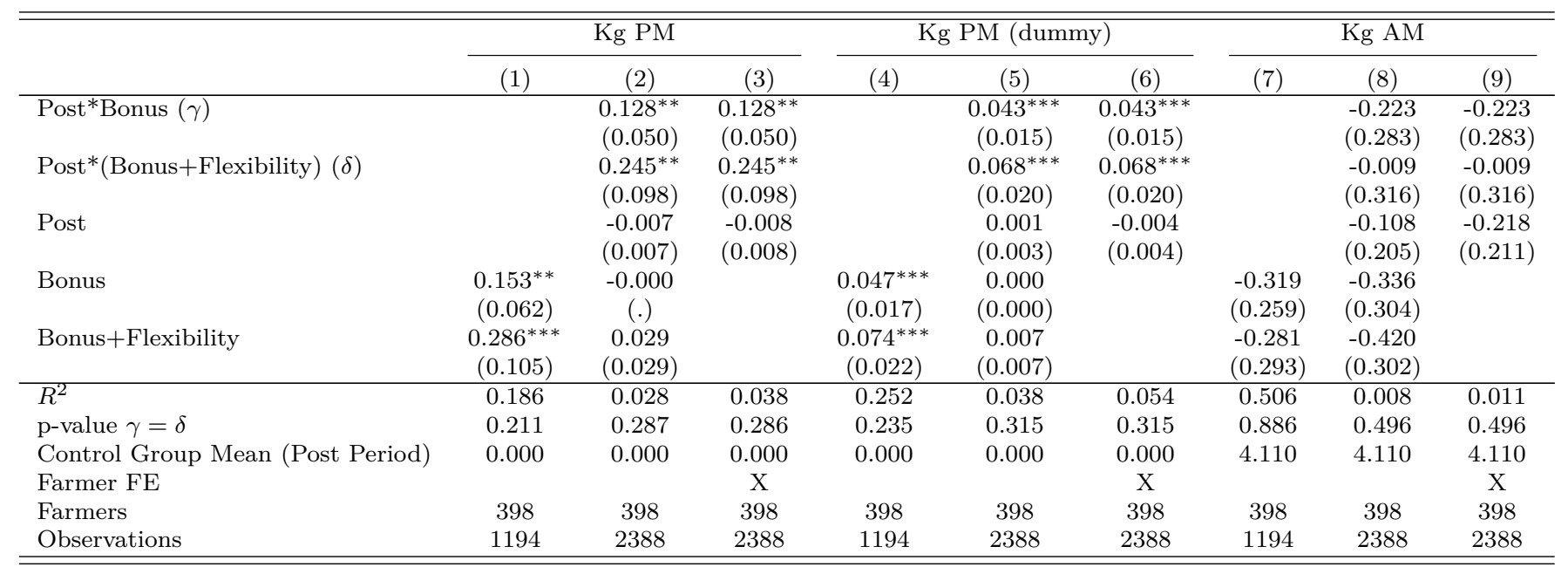

Notes: The table presents the results of the Price and Flexibility randomized experiment described in Section 5.2 The experiment targeted farmers selling to the coop in the morning but not in the afternoon at baseline. Farmers in the Bonus group received an increase in milk price of 10 Kenyan shillings for afternoon deliveries. Farmers in the Bonus+Flexibility group received the same price increase and the option to be paid daily. The table reports three measures of daily deliveries: kilograms delivered in the afternoon; a dummy for whether the farmer delivers any milk in the afternoon; kilograms delivered in the morning. For each farmer, the regression includes a maximum of six observations. Three observations come from the experiment days $($ Post $=1)$ and three from the same calendar days in the previous month $($ Post $=0)$. For each outcome, the first model (Columns (1), (4), (7)) is an OLS run only on the three Post observations, controlling for the average level of the outcome in the three baseline observations. The second model (Columns (2), (5), $(8)$ ) is a difference-in-differences. The third model (Columns (3), (6), (9)) adds farmer fixed effects to the difference-in-differences. In Columns (1), (4), and (7), the row " $p$-value $\gamma=\delta$ " reports the p-value from testing equality of the coefficients on Bonus and Bonus+Flexibility. In the other columns, the row "p-value $\gamma=\delta$ " reports the p-value from testing equality of the coefficients Post ${ }^{*}$ Bonus and Post*(Bonus + Flexibility). Standard errors are clustered at the farmer level. ${ }^{*} \mathrm{p}<0.1,{ }^{* *} \mathrm{p}<0.05,{ }^{* * *} \mathrm{p}<0.01$. 


\section{Appendix}

\section{A Theory Appendix}

\section{A.1 Proofs}

\section{Proof of Proposition 1.}

To avoid a lengthy taxonomy of cases, the analysis focuses on interior solutions. This is without loss of generality as there always exists a rescaling of parameters $D$ and $\Delta$ such that all assumptions are verified and an interior solution exists. We consider the three scenarios described in the main text. For notational simplicity, we also assume buyers pay a per period interest rate of $1 / \delta$ when paying at the end of the month. This eliminates a trade credit motive and delivers a more transparent algebra without affecting any of the results.

A Liquid Saving Technology: Consider the case of a producer who, in a given month, must save on her own using the liquid saving technology. In $t=2$, the producer decides to save $\delta D$ and purchase the indivisible good in $t=3$, rather than consuming, if $v+s_{1}-\delta D+\beta \delta \Delta \geq v+s_{1}$, where $s_{1}$ is the amount the producer saved in $t=1$. The inequality holds if $\beta \geq \frac{D}{\Delta} \equiv \beta_{1}$. In addition, since $v / \delta<D$, self 1 must also save $s_{1}^{P}=\delta^{2}(D-v / \delta)$. She chooses to do so if $v-s_{1}^{P}+\beta \delta^{2} \Delta \geq v(1+\beta \delta)$, or $\beta \geq \frac{D}{\Delta}-\frac{v}{\delta \Delta} \equiv \tilde{\beta}<\beta_{1}$.

Infrequent Payments: Consider now the case in which the buyer pays a price per liter $p$ at the end of the month $(t=3)$. Self 2 will save $s_{2}^{*}=\delta\left(D-p x_{1} / \delta\right)$ for the indivisible good if $v-\left(\left(D-p x_{1}\right) / \delta\right)+\beta \delta \Delta>v$ or $x_{1} \geq \frac{\delta^{2}(D-\beta \Delta)}{p} \equiv x_{1}^{*}$. In turn, self 1 will be willing to provide this minimum amount of illiquid savings to self 2 if $\left(1-x_{1}^{*}\right) v+\beta \delta\left(\left(v-s_{2}^{*}\right)+\delta \Delta\right) \geq(1+\beta \delta) v$, which holds if $p \geq v \frac{D-\beta \Delta}{\beta \Delta(1-\beta)} \equiv p_{2}$. The infrequent payment helps if the buyer can make non-negative profits, i.e., $p \leq v$. Setting $p=v$ yields $\beta \geq 1-\sqrt{\frac{\Delta-D}{\Delta}} \equiv \beta_{2}$. Simple algebra shows that $\beta_{2}<\beta_{1}$. When $\beta \in\left[\beta_{2}, \beta_{1}\right)$ producers can buy the indivisible good if the large buyer provides infrequent payments but not by saving on their own. Note that the threshold $\beta_{2}$ corresponds to the case in which producers sell at $v$ and save in a commitment saving account with large withdraw fees before $t=3$.

Infrequent Payments with a Relational Buyer: As discussed in the paper, a buyer who offers infrequent payments can further help producers save by threatening to punish them if they fail to sell (and thus to save) on a regular basis. We focus on the stationary relational contract that maximizes the buyer profits subject to incentive constraints for the producer. In the resulting relational contract the large buyer sets a price $p$ for deliveries and requires the producer to sell $x_{1}$ and $x_{2}$ in period 1 and 2 respectively, such that $p\left(x_{1} / \delta^{2}+x_{2} / \delta\right)=D$. If the producer ever deviates, the large buyer will never accept deliveries from that producer in the future.

Self 2 sells to the large buyer if $v\left(1-x_{2}^{* *}\right)+\beta \delta\left(\Delta+\delta V^{\Delta}\right) \geq v+\beta \delta\left(\delta V^{0}\right)$, where $x_{2}^{* *}=\delta\left(\frac{D}{p}-\frac{x_{1}}{\delta^{2}}\right)$, $V^{\Delta}=\frac{\left(1-x_{1}\right) v+\delta\left(1-x_{2}\right) v+\delta^{2} \Delta}{1-\delta^{3}}$ and $V^{0}=\frac{1+\delta}{1-\delta^{3}} v$ are the continuation values when maintaining or leaving the relation, respectively. The inequality holds if $x_{1} \geq \delta^{2} \frac{D v\left(1-(1-\beta) \delta^{3}\right)-p \beta \Delta}{p v\left(1-\delta^{3}\right)} \equiv x_{1}^{* *}$. Thus, $x_{1}^{* *}$ is the minimum level of (infrequent payment) sales that self 1 must make to the large buyer to induce self 2 to sell to the large buyer, too. Self 1 will chose to sell this amount if $p \geq D v \frac{1+(1-\beta)^{2} \delta^{3}}{(2-\beta) \beta \Delta} \equiv p_{3}$.

Under the assumption of perfect contract enforcement and no buyer default, the relational contract helps producers buy the indivisible good as long as the large buyer can make zero profit from the relationship, i.e., if $p \leq v$. Setting $p=v$ and rearranging terms yields $\beta \geq 1-\sqrt{\frac{\Delta-D}{\Delta-D \delta^{3}}} \equiv \beta_{3}$. Simple algebra establishes $\beta_{3}<\beta_{2}$. When $\beta \in\left[\beta_{3}, \beta_{2}\right.$ ), the producer buys the indivisible good under the relational contract (which features both illiquid payment and punishment threat), but not with illiquid payments alone. Even a producer with access to an illiquid saving technology might not use it if the buyer provides illiquid payments with the additional threat of future punishment if the producer deviates from the plan.

Proof of Proposition 2. We now consider the case in which infrequent payments must be self-enforcing, 
i.e., buyers must be given incentives to honor their promises to pay at the end of the month. While, in principle, both the large and the small buyers can offer infrequent payments, we characterize an equilibrium in which the large buyer sets prices such that small buyers are not able to credibly promise infrequent payments. That is, we construct an equilibrium such as the one described in Proposition 3. We first check that in equilibrium there are no profitable unilateral deviations and then show that there are intermediate values of $\beta$ that satisfy all the conditions.

Proposed Equilibrium: In the proposed equilibrium the large buyer first sets the price for infrequent payments ${ }^{24}$ The small traders decide whether to offer daily or infrequent payments and at which price. Finally producers either accept or reject the relational contract offered by the large buyer and make their sales and purchases decisions.

Large Buyer: The large buyer sets the price to maximize profits subject to three constraints: i) producers must be willing to sell; ii) no other trader can credibly offer infrequent payments; and iii) the large buyer must be credible. Generally, when such an equilibrium exists iii) cannot be binding.

Let us now consider the large buyer's possible deviations. Two cases must be distinguished: case 1:) the producer's participation constraint is binding; case 2:) the small traders' incentive constraint binds. In both cases the large buyer has no incentive to default on promised monthly payments, as she would lose the future rents. In both cases she also has no incentives to lower the price. If the producer's participation is binding that would lower the volumes bought; if the small trader's incentive constraint is binding traders would then become credible at a larger price and the buyer wouldn't make any profit. The large buyer has thus no incentives to deviate.

Producers: In case 1 producers do not have incentives to deviate: they are indifferent between sticking to the plan versus deviating and never being able to buy the indivisible good in the future. In case 2 they would be made strictly worse-off by such a deviation.

Small Traders: Small traders also have no incentives to deviate. In the proposed equilibrium they make zero profits. Given the price set by the large buyer they can't credibly offer infrequent payments. If they do so, they would still make zero profit ${ }^{25}$

We have thus checked that the proposed strategy profile constitutes a subgame-perfect Nash equilibrium in which no player has a unilateral incentive to deviate. We now check that all the required conditions can indeed be verified for intermediate values of impatience $\beta$.

Existence: Consider a deviation in which a small buyer offers a producer infrequent payments at price $p$ and denote with $\hat{x}_{t}^{S}$ the resulting quantity the trader buys in period $t=1,2$. If the producer accepts the small buyer's offer, she is punished by the large buyer who will refuse to purchase from her in the future. To attract the producer, then, the small buyer must offer a deal that allows the producer to purchase the indivisible good solely from his promised low frequency payment. The deviating small buyer faces the maximum temptation in $t=3$, once he has already purchased the output and needs to pay for deliveries $\hat{x}_{1}^{S}$ and $\hat{x}_{2}^{S}$. Let's consider a one-period deviation where the small buyer defaults for one month and then reverts to pay future sales with

\footnotetext{
${ }^{24}$ To be precise, at the beginning of the game the large buyer posts a plan, i.e., a sequence of prices and buying policies for all future periods on- and off- the equilibrium path. As is well-known, in the optimal stationary equilibrium of this game the two formulations are equivalent (Abreu, 1988) and we therefore avoid the unnecessary notational complexity associated with the plan.

${ }^{25}$ The assumption that buyers either offer monthly or daily payments, but not both, rules out a deviation in which small traders offer a contingent plan in which monthly payments are offered only to those producers that have defaulted on the large buyer. If they could do so (or if we consider asymmetric equilibria in which some small traders specialize in offering infrequent payments to defaulting producers) we need to distinguish the two cases. In case 1 the producer wouldn't accept the offer: the producer constraint is binding at a monthly price that is larger than what traders could credibly offer. In case 2, instead, the defaulting producer would accept the deal. This contingent plan would thus change the value of defaulting on the large buyer for the producer. This would shrink the set of parameters for which a case 2 equilibrium arises, without altering any of the other conclusions.
} 
infrequent payments upon meeting in the outside market a producer willing to sell to him (which happens in each period with probability $\gamma) 26$

The continuation value of such a relationship with a producer is given by $V^{S}=\sum_{s=0}^{\infty} \delta^{3 s}(v-p)\left(\hat{x}_{1}^{S}+\delta \hat{x}_{2}^{S}\right)$. The small buyer's offer is credible if paying the promised amount and continuing the relationship gives a higher discounted value than defaulting and then searching for an uninformed producer in the outside market, that is: $-\frac{p}{\delta^{2}}\left(\hat{x}_{1}^{S}+\delta \hat{x}_{2}^{S}\right)+\delta V^{S} \geq \delta \sum_{m=0}^{\infty} \gamma(1-\gamma)^{m} \delta^{3 m} V^{S}$. Simple algebra delivers: $p \leq \delta^{3}(1-\gamma) v \equiv$ $p^{S}$. The empirical version of the trader IC constraint used in the calibration (Equation 1) is similarly derived. We consider a buyer who sources a constant amount of milk, $x$, and pays the same unit price, $p$, across the 30 days of the month (these assumptions are supported by the data). The incentive constraint is $-30 p x+\delta \sum_{s=0}^{\infty} \delta^{30 s}\left(\left(\sum_{t=0}^{29} \delta^{t} v x\right)-30 \delta^{29} p x\right) \leq \delta \sum_{u=0}^{\infty} \delta^{30 u}(1-\gamma)^{u} \sum_{s=0}^{\infty} \gamma \delta^{30 s}\left(\left(\sum_{t=0}^{29} \delta^{t} v x\right)-30 \delta^{29} p x\right)$, which simplifies to $p>\frac{1}{30} \delta(1-\gamma) \frac{1-\delta^{30}}{1-\delta} v \equiv p_{\text {empirical }}^{T}$.

The large buyer sets the price to maximize profits subject to three constraints. First, he must pay a price higher than the highest price at which small buyers can credibly promise infrequent payments, $p \geq p^{S}$. Second, he must pay a price high enough to induce producers to sell for infrequent payments. This minimum price, which we denote as $p^{P}$, is equal to $p_{3}$ defined in the proof of Proposition 1 . At this price, the large buyer must be credible, which is the case if $p^{P} \leq \delta^{3} v$. Simple algebra shows that this is the case if $\beta \geq 1-\sqrt{\frac{\Delta-\frac{D}{\delta^{3}}}{\Delta-D}} \equiv \beta_{4}>\beta_{3}$. There always exists a set of parameters such that $\beta_{4}<\beta_{1}$, and thus the producer can save through a relational contract with infrequent payments (and imperfect enforcement), but not on her own. The large buyer then sets $p^{*}=\max \left\{p^{S}, p^{P}\right\}$.

\section{A.2 Extensions}

(No) Bundling of Monthly and Cash Payments. So far we have assumed that the large buyer does not offer daily payments. Could the large buyer possibly profit from offering daily payments as well? To begin with, note that free entry implies that buyers make zero profits on daily payments. This implies that the only way the large buyer could profit from offering daily payments is through a bundling contract in which monthly payments are offered only to those producers that supply all their production in both periods. Three considerations suggest that such bundling might not be profitable. First, if the producer's participation constraint is already binding bundling would not increase profits. If producers are heterogeneous but discrimination is not possible, bundling might even decrease profits. Second, to offer daily payments, the large buyer might have to incur higher costs. For example, it would have to monitor milk collectors to handle cash properly. These higher costs do not bring profits in the daily payment market, and might reduce profits making the large buyer less credible in offering the monthly payments. Finally, by offering daily payments the large buyer could make it harder for the producer to sustain the commitment plan, thereby undoing its main source of profits.

Producer's Utility and Heterogeneity. The model assumes that producers have a linear utility function. Allowing a concave utility function and/or that producers also derive utility from consumption of the divisible good in $t=3$ would make algebra more cumbersome without providing additional insights or altering the key results.

\footnotetext{
${ }^{26}$ In the model, default on one farmer triggers punishment from farmers the trader tries to match in subsequent periods, but not from other farmers the buyer is currently buying from. Allowing for this collective punishment would imply that the optimal deviation for the trader would be defaulting on all the farmers he buys from. If the opportunity to find new uninformed farmers, $\gamma$, is invariant with size, the trader incentive constraint when allowing for collective punishment would be identical to our baseline framework. However, $\gamma$ may be decreasing in the number of farmers the buyer deals with. In practice, most traders are small itinerant buyers with limited capacity. We therefore abstract from differences in size across traders and focus on the difference between the traders and the large credible buyer. The model generalizes to the case with heterogeneous costs of default: $\gamma_{0} \leq \gamma_{1} \leq \gamma_{2}<\ldots<\gamma_{N}$.
} 
Similarly, it is also straightforward to extend the model to allow for producers heterogeneity in, e.g., the degree of time-inconsistency $\beta$ or the valuation for the indivisible good $\Delta$. Consider for instance the case in which $\Delta_{i}$ differs across producers and is distributed according to a strictly increasing and twice continuously differentiable cumulative function $G\left(\Delta_{i}\right)$ on support $\Delta_{i} \in[0, \infty)$. In this case the key result of the theory that the price paid by buyers offering monthly payments is lower than the daily price would still emerge in equilibrium. In addition, there would be a sorting of producers with heterogeneous $\Delta_{i}$ into different marketing channels 27

Payment Frequencies. The model focuses on the case in which there are only two payment frequencies: daily and monthly. This is in line with evidence from our context suggesting that the vast majority of traders do not offer any delayed payment, even at weekly frequencies. A natural question is why traders in practice do not offer delayed payments with shorter - e.g., weekly, or bi-weekly - frequencies. This would reduce the amount they promised to pay to producer and give them more credibility. While we do not have conclusive evidence on this, we conjecture the following as a plausible explanation. Time-inconsistent producers might not be able to carry forward intermediate amounts of money resulting from, e.g., weekly sales to buy indivisible goods at the end of the month. That is, producers would only be able to buy smaller indivisible goods, for which they might not have a demand. This lack of demand could be in itself the result of producers' adaptation to the equilibrium with only monthly payments from the coop.

Access to Credit. While the model emphasizes the role of saving constraints, it also makes the stark assumption that producers cannot borrow. The logic of the model survives the introduction of an informal credit market in which producers borrow from lenders (including buyers). The reason is as follows. In the presence of limited contract enforcement, an informal credit market will develop only if the producer can commit to repay the informal lender. It can be shown that there are parameters configurations such that a producer isn't able to credibly borrow to purchase the lumpy good, but can stick to a saving plan that allows him to (and vice versa).

When the producer can both credibly borrow in the informal market as well as stick to a saving plan, her welfare under the two scenarios depends on two opposing forces: competition vs. over-borrowing. Buyers do not face credibility issues when extending loans. If multiple buyers can offer loans, competition pushes prices up. On the other hand, time-inconsistent producers might end up borrowing for lumpy goods their future selves regret if intra-personal rules are not powerful enough. So, even when an informal borrowing market is available, producers might prefer the discipline provided by saving through the large buyer.

Furthermore, the presence of large buyers offering a saving tool undermines producers' credibility when borrowing from traders: in the event of a default against a trader, the producer can still buy desired lumpy goods in the future by selling to the large buyer. By offering this saving service, the large buyer prevents competition from traders offering credit without having to take on any default risk. In our context, producers have limited access to well-functioning formal credit markets, but they could borrow from either the large buyer, traders, or other informal sources to finance their lumpy consumption. Evidence from the survey reveals however that only $26 \%$ of producers borrow from any source for their dairy business; and very few borrow from either traders or the coop.

Intra-Personal Plans. In the main text, we abstracted from producers' personal strategies across periods (see, e.g., Strotz, 1955, Laibson, 1997, Bernheim et al. 2015). These strategies could allow the producer to save the necessary amount to buy the indivisible good. The intuition is as follows. Consider a producer that decides to follow a plan in which she saves sufficient funds to purchase the indivisible good on

\footnotetext{
${ }^{27}$ These insights are robust to the case in which the large buyer can perfectly discriminate across producers. With multiple large buyers competing perfect discrimination would of course not be possible. In practice, the cooperative bylaws rule out price discrimination possibly due to prevailing norms and the concern that producers could perceive to be treated unfairly. We have also assumed that all buyers maximize profits. The framework can be extended to the case in which the large buyer (which is a coop) also cares about producers' welfare. Provided the assumption of limited contract enforcement is maintained the main results wouldn't change.
} 
her own. Should any of her selves ever deviate, all future selves consume all their endowment every period and the indivisible good is never purchased again. By relaxing the incentive constraint, infrequent payments would still help.

In our simple model with perfect monitoring the intra-personal rule perfectly mimics the relational contract with the buyer: if the producer can punish herself by committing to never buy the indivisible again she will achieve the same level of deterrence afforded by the relational contract with the buyer. In practice (and in more complicated models) we conjecture that the relational contract with the buyer could still help achieving saving targets even those producers that can implement inter-temporal saving strategies. For example, the producer might find it difficult to carry out the punishment because her future selves have a strong temptation to renegotiate. Such renegotiations might not be easily prevented since the producer also has strong incentive to forget what caused deviating from the plan in the past, as in Bénabou and Tirole (2004). The buyer has no incentive to renegotiate the punishment as such a renegotiation could lead other producers to reduce supplies and would have incentives to remind the producers about her past deviations. This would give the buyer a stronger ability to punish producers' deviating selves.

\section{B Survey Evidence}

\section{B.1 Survey Evidence on Farmers' Demand for Infrequent Pay- ments}

The demand experiment results are consistent with, and further supported, by several additional pieces of survey evidence. First, as discussed in Section 3.3. Figure 1.Panel A shows that many farmers report they want the coop to may monthly and that monthly payments help save.

Second, Appendix Table C.1 suggests that having another regular occupation or being a larger producers is associated with a lower likelihood that the farmer states that the coop helps reaching the saving goals (Columns 3 and 4). In the same table, the role of the payment frequency in achieving the saving goals is particularly large for present-biased farmers, consistent with a certain degree of sophistication in our target population.

Third, correlation patterns from a very short survey administered to a representative sample of the overall farmers population in the area (i.e., including farmers that do not sell to the coop) further supports the hypothesis that the coop payments may be related to farmers' savings. Appendix Table C.2 shows that farmers who set saving goals are 20 percentage points more likely to sell to the coop ( $86 \%$ vs. $66 \%$ ) and that farmers selling to the coop are more likely to reach their saving goals.

Fourth, farmers report using money earned from the traders and from the coop for different purposes, as shown in Appendix Figure C.1. The monthly payment from the coop is predominantly (almost 40\%) used to finance lumpy expenses in the dairy business, such as purchase of feed and equipment. The largest share of traders' daily payments is instead spent on current expenses, such as purchasing food (55\%) ${ }^{28}$ In sum, several additional pieces of survey evidence supports the results from the demand experiments: farmers value the coop's infrequent payments as those help overcoming saving constraints.

\section{B.2 Survey Evidence on Buyers}

As discussed in Section 3.3 small traders pay a higher price than the coop. This result holds in multiple seasons and years. First, in the baseline survey for the randomized experiment described in Section 5 we asked farmers about average trader price in December 2013, March 2014, and June 2014. These are 37-38

\footnotetext{
${ }^{28}$ The findings are consistent with the model of Banerjee and Mullainathan (2010) and with evidence from Haushofer and Shapiro (2016), who find that monthly transfers from an unconditional cash transfer program are more likely than lump-sum transfers to improve food security, while lump-sum transfers are more likely to be spent on lumpy expenses.
} 
KSh per liter. We also ask about the price paid by the best trader and the figures are very similar, consistent with a competitive trading sector and low dispersion in daily payment prices. In this period the coop was paying between 29 and $31 \mathrm{KSh}$ per liter. Second, for our demand experiment, we ask farmers about trader price in October 2014. The average price was KSh 38. The coop price in this period was KSh 31-32. Third, for the supply experiment described in section 4 we asked traders about the price they payed for milk in July 2017. Traders reported an average price of KSh 43, with average "high price" being KSh 47 and "low price" KSh 41. In this period, the coop price was KSh 35-36.

There are many reasons why farmers may be willing to accept a lower price from the coop. First, $75 \%$ of respondents report a sense of pride from selling to the coop. Second, farmers may take loans from the coop. However, survey data suggest only $7.5 \%$ do and "loans" mostly take the form of advances on milk already delivered ${ }^{29}$ The coop also sells inputs at some of its collection centers: This may reduce transaction costs, but $90 \%$ of farmers report being unsatisfied with the inputs' quality and prices. Third, while farmers report that most traders are available every day, the coop's demand may be more reliable in peak production season. However, since the coop does not condition present purchases on past deliveries, coop's purchase guarantee in the peak season cannot explain sales to the coop in other months. Fourth, about one-quarter of the farmers report they have attended a training organized by the coop over the last year. Fifth, there is essentially no quality testing done by either the coop or the large buyer, thus the difference in price cannot be driven by systematic differences in milk quality. Sixth, farmers may bear a higher transport cost when bringing milk to traders than to the coop collection center. However, average distance between the farmer and the sale point seems higher for the coop. Finally, we note the cooperative does not make second payments at the end of the year.

${ }^{29}$ The coop does not offer asset-collateralized loans such as the ones described in Jack et al. (2016). 


\section{Appendix Figures and Tables}

\section{C.1 Appendix Figures}

Figure C.1: Usage of Milk Earnings

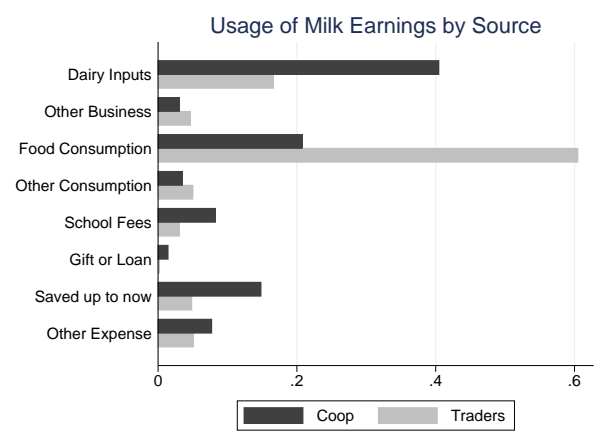

Notes: The figure describes how farmers in the baseline $(\mathrm{N}=595)$ use milk earnings from the coop and from other buyers, respectively. For each type of buyer, we compute the share of expenses on an item, relative to the total earned by the farmer from that buyer.

Figure C.2: Trader Incentive Constraint Calibration: Robustness
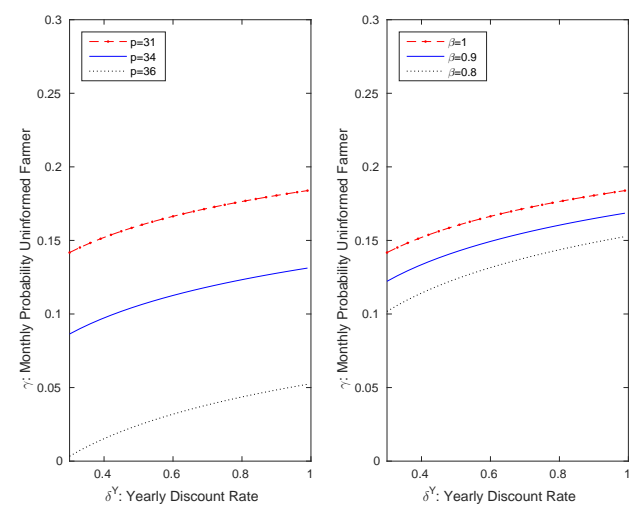

Notes: The figure presents robustness check to Figure 5 In the left graph, we vary the purchase price a trader would be able to offer when paying infrequently. If part of the observed price gap comes from other benefits the coop offers, the trader will have to offer a higher price. This reduces the $\gamma$ threshold that makes the trader unable to commit. In the right graph, we allow the trader to be $\beta \delta$ and show to which extent an increase in time-inconsistency (i.e., lower $\beta$ ) reduces the threshold $\gamma$ threshold. 
Figure C.3: Number of Days with Deliveries to the Coop

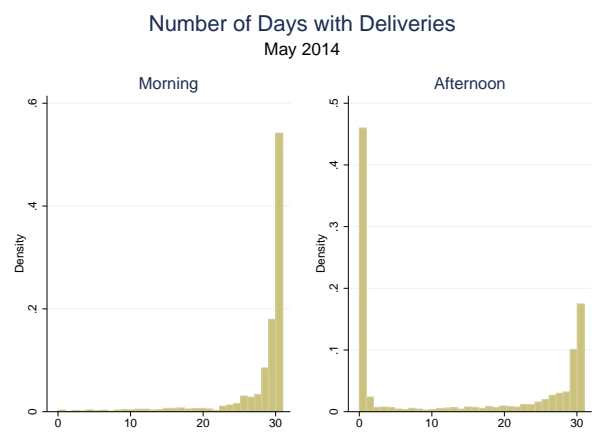

Notes: The left (right) histograms present the distribution of the farmer-level number of days with positive deliveries to the coop in the morning (afternoon) in a month (measured in May 2014). The sample includes all the farmers making at least one sale to the coop $(\mathrm{N}=1,901)$ The figure shows that many farmers sell to the coop (almost) every day of the month and (almost) never in the afternoon.

\section{Figure C.4: Farmers' Loyalty to the Coop}

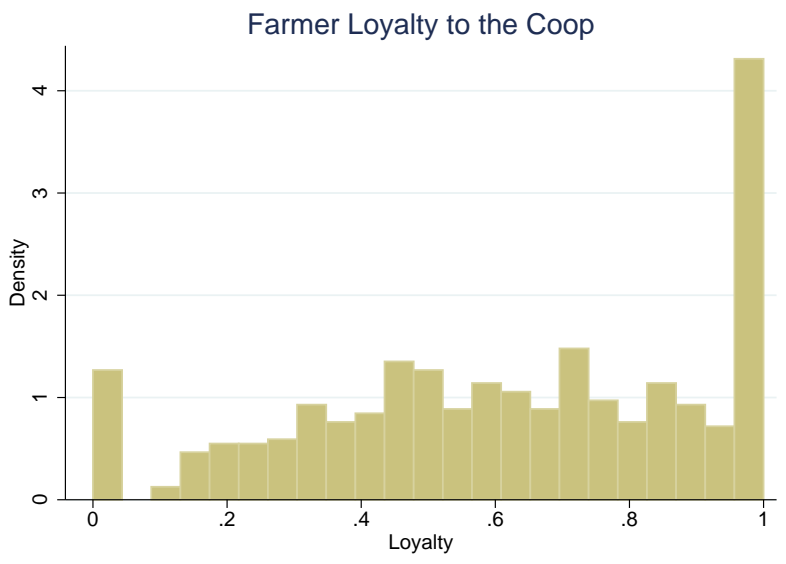

Notes: The Loyalty variable is defined as the ratio between sales to the coop and production available for sales among farmers in the baseline survey $(\mathrm{N}=595)$. Production available for sales is defined as the difference between production and home consumption (including feeding calves). Deliveries to the coop are obtained from cooperative records. 


\section{C.2 Appendix Tables}

Table C.1: Baseline Correlations

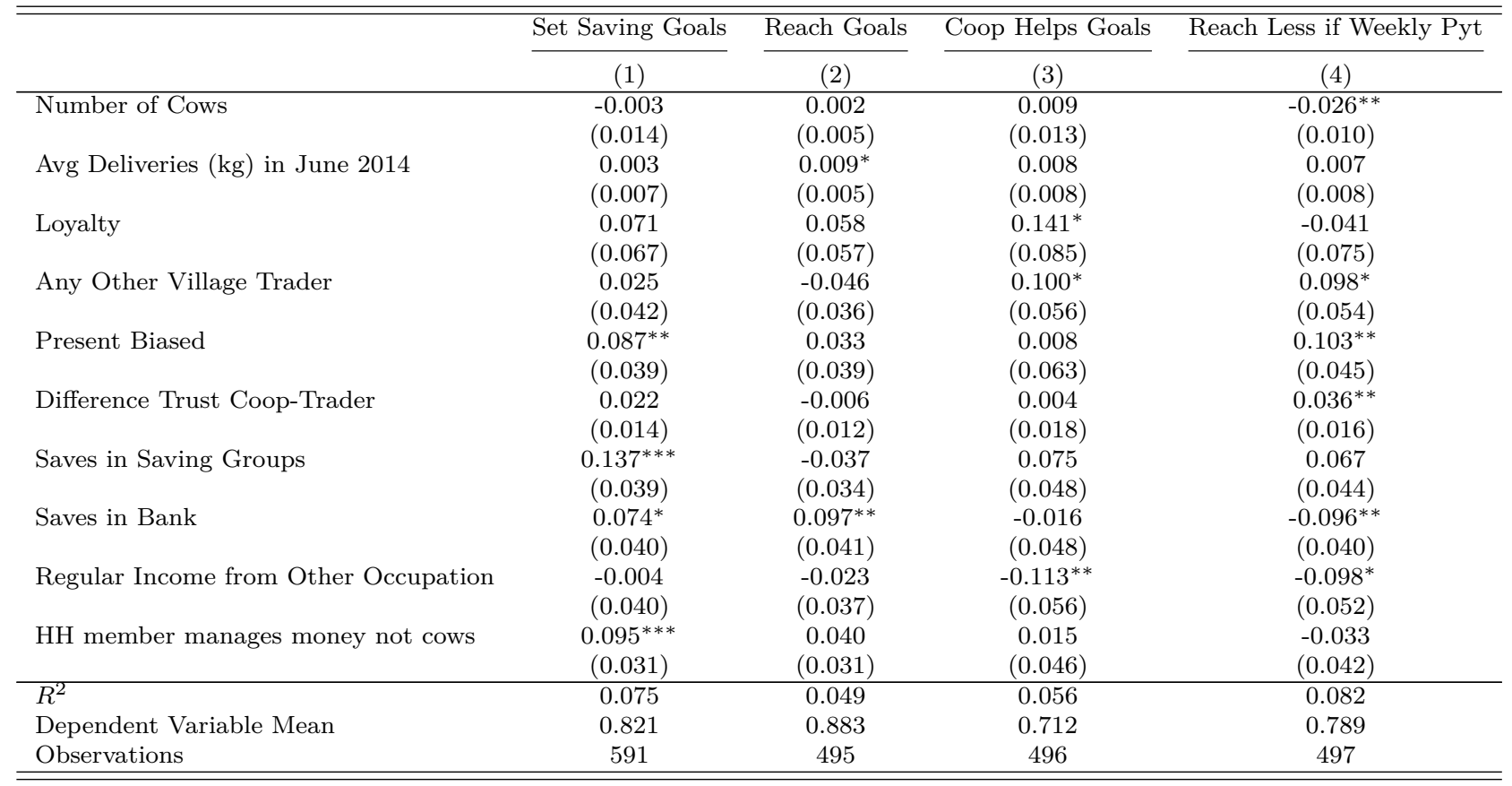

Notes: The table presents correlation between several measures of saving behavior and other farmer covariates, measured in the baseline survey for the Price and Liquidity Experiment, described in Section 5.2. Avg Daily Deliveries are from coop administrative data. Both production and delivery variables are measured in kilograms. Loyalty variables are defined as ratios between sales to the coop and production available for sale (defined as the difference between production and home consumption, including feeding calves). A farmer is defined as present biased if she is more impatient when splitting KSh 200 between today and next week than between next week and the subsequent one. Trust for either the coop and the buyer is measured on an index from 1 to 4 . Therefore, their difference can span -3 to 3. Regular Income from Other Occupation refers to permanent employee, civil servant, artisan, trader, and self-employed. For each of the covariates, the regression also includes a binary indicator for whether that covariate is missing (and missing values in the variables are replaced with an arbitrary negative value). Standard errors are robust to heteroskedasticity. ${ }^{*} \mathrm{p}<0.1,{ }^{* *} \mathrm{p}<0.05,{ }^{* * *} \mathrm{p}<0.01$. 
Table C.2: Farmer Saving Behavior and Sales to the Coop

\begin{tabular}{lccccccc}
\hline \hline & \multicolumn{3}{c}{ Set Saving Goals } & & \multicolumn{3}{c}{ Reach Goals } \\
\cline { 2 - 3 } \cline { 7 - 8 } & $(1)$ & $(2)$ & $(3)$ & & $(4)$ & $(5)$ & $(6)$ \\
\hline Sells to Coop & $0.206^{* * *}$ & $0.184^{* * *}$ & $0.206^{* * *}$ & & $0.358^{* * *}$ & $0.255^{*}$ & 0.173 \\
& $(0.040)$ & $(0.042)$ & $(0.047)$ & & $(0.131)$ & $(0.133)$ & $(0.149)$ \\
\hline Y Mean (No-Coop) & 0.664 & 0.664 & 0.664 & & 3.207 & 3.207 & 3.207 \\
N.Cows & $\mathrm{N}$ & $\mathrm{Y}$ & $\mathrm{Y}$ & & $\mathrm{N}$ & $\mathrm{Y}$ & $\mathrm{Y}$ \\
Village FE & $\mathrm{N}$ & $\mathrm{N}$ & $\mathrm{Y}$ & & $\mathrm{N}$ & $\mathrm{N}$ & $\mathrm{Y}$ \\
Observations & 408 & 408 & 408 & & 302 & 302 & 302 \\
\hline \hline
\end{tabular}

Notes: The analysis uses data from the dairy farmer listing exercise, which targeted a random sample of dairy farmers. The binary variable "Set saving goals" is not missing for 408 of these farmers. The variable "Reach Goals" takes value from 1 (never reach the goals) to 6 (always reach them). The variable is defined only for those farmers who state that they set saving goals. Standard errors are robust to heteroskedasticity. ${ }^{*} \mathrm{p}<0.1,{ }^{* *} \mathrm{p}<0.05,{ }^{* * *} \mathrm{p}<0.01$. 
Table C.3: Price and Liquidity Experiment: Balance Table

\begin{tabular}{|c|c|c|c|c|c|c|c|}
\hline & $\begin{array}{c}\text { Bonus } \\
{[\mathrm{M}]}\end{array}$ & $\begin{array}{c}\text { Bonus+Flex } \\
{[\mathrm{F}]}\end{array}$ & $\begin{array}{c}\text { Control } \\
{[\mathrm{C}]}\end{array}$ & $\begin{array}{c}\text { P-value } \\
{[\mathrm{M}-\mathrm{F}]}\end{array}$ & $\begin{array}{c}\text { P-value } \\
{[\mathrm{M}-\mathrm{C}]}\end{array}$ & $\begin{array}{c}\text { P-value } \\
{[\mathrm{F}-\mathrm{C}]}\end{array}$ & $\mathrm{N}$ \\
\hline Male Respondent & $\begin{array}{l}.3706 \\
(.4846)\end{array}$ & $\begin{array}{l}.4765 \\
(.5011)\end{array}$ & $\begin{array}{l}.4123 \\
(.4948)\end{array}$ & $.052^{*}$ & .825 & .319 & 389 \\
\hline Respondent Age & $\begin{array}{c}58.39 \\
(15.90)\end{array}$ & $\begin{array}{c}54.96 \\
(15.98)\end{array}$ & $\begin{array}{c}56.12 \\
(15.05)\end{array}$ & .136 & .323 & .455 & 387 \\
\hline Household size & $\begin{array}{l}4.945 \\
(2.185)\end{array}$ & $\begin{array}{c}5.306 \\
(1.928)\end{array}$ & $\begin{array}{l}5.163 \\
(2.064)\end{array}$ & .133 & .73 & .425 & 395 \\
\hline Number of Cows & $\begin{array}{l}1.383 \\
(.6874)\end{array}$ & $\begin{array}{l}1.346 \\
(.6754)\end{array}$ & $\begin{array}{l}1.448 \\
(.6904)\end{array}$ & .849 & .426 & .28 & 394 \\
\hline Dairy Production (kg) & $\begin{array}{l}11.44 \\
(7.026)\end{array}$ & $\begin{array}{l}11.11 \\
(4.948)\end{array}$ & $\begin{array}{c}11.00 \\
(5.450)\end{array}$ & .894 & .617 & .803 & 389 \\
\hline Average Daily Deliveries in Sep 2014 & $\begin{array}{c}3.963 \\
(2.257)\end{array}$ & $\begin{array}{l}4.051 \\
(2.413)\end{array}$ & $\begin{array}{c}4.216 \\
(2.262)\end{array}$ & .826 & .199 & .302 & 398 \\
\hline Loyalty & $\begin{array}{l}.6632 \\
(.2476)\end{array}$ & $\begin{array}{l}.6582 \\
(.2516)\end{array}$ & $\begin{array}{l}.6713 \\
(.2529)\end{array}$ & .597 & .881 & .618 & 376 \\
\hline Loyalty AM & $\begin{array}{l}.7814 \\
(.2225)\end{array}$ & $\begin{array}{l}.7669 \\
(.2221)\end{array}$ & $\begin{array}{l}.7611 \\
(.2210)\end{array}$ & .405 & .659 & .743 & 383 \\
\hline Loyalty PM & $\begin{array}{l}.4978 \\
(.5004)\end{array}$ & $\begin{array}{l}.5057 \\
(.4997)\end{array}$ & $\begin{array}{l}.5429 \\
(.4943)\end{array}$ & .552 & .742 & .213 & 378 \\
\hline Hire workers for dairy & $\begin{array}{l}.2229 \\
(.4176)\end{array}$ & $\begin{array}{l}.2516 \\
(.4354)\end{array}$ & $\begin{array}{l}.2551 \\
(.4381)\end{array}$ & .314 & .625 & .835 & 397 \\
\hline Any Other Village Trader & $\begin{array}{l}.8367 \\
(.3708)\end{array}$ & $\begin{array}{l}.8807 \\
(.3251)\end{array}$ & $\begin{array}{l}.7755 \\
(.4193)\end{array}$ & .25 & .468 & $.079^{*}$ & 396 \\
\hline Present Biased & $\begin{array}{l}.1313 \\
(.3390)\end{array}$ & $\begin{array}{l}.1103 \\
(.3144)\end{array}$ & $\begin{array}{l}.1086 \\
(.3129)\end{array}$ & .62 & .538 & .816 & 374 \\
\hline Difference Trust Coop-Trader & $\begin{array}{c}.7591 \\
(1.121)\end{array}$ & $\begin{array}{c}.9851 \\
(1.126)\end{array}$ & $\begin{array}{c}.9418 \\
(1.109)\end{array}$ & .158 & .488 & .523 & 358 \\
\hline Saves in Saving Groups & $\begin{array}{l}.6418 \\
(.4810)\end{array}$ & $\begin{array}{l}.7302 \\
(.4452)\end{array}$ & $\begin{array}{l}.7395 \\
(.4411)\end{array}$ & .121 & $.09 *$ & .831 & 396 \\
\hline Saves in Bank & $\begin{array}{l}.7260 \\
(.4475)\end{array}$ & $\begin{array}{l}.7105 \\
(.4550)\end{array}$ & $\begin{array}{l}.7938 \\
(.4066)\end{array}$ & .822 & .274 & .224 & 395 \\
\hline Regular Income from Other Occupation & $\begin{array}{l}.2094 \\
(.4083)\end{array}$ & $\begin{array}{l}.2105 \\
(.4090)\end{array}$ & $\begin{array}{l}.2142 \\
(.4124)\end{array}$ & .961 & .572 & .897 & 398 \\
\hline HH member manages money not cows & $\begin{array}{l}.2463 \\
(.4324)\end{array}$ & $\begin{array}{l}.2739 \\
(.4475)\end{array}$ & $\begin{array}{l}.3333 \\
(.4739)\end{array}$ & .694 & .271 & .146 & 377 \\
\hline
\end{tabular}

Notes: The table reports summary statistics and balance tests for the Price and Flexibility randomized experiment described in Section 5.2. Farmers in the Bonus group received an increase in milk price of 10 Kenyan shillings for afternoon deliveries. Farmers in the Bonus+Flexibility group received the same price increase and the option to be paid daily. Avg Daily Deliveries are from coop administrative data. Both production and delivery variables are measured in kilograms. Loyalty variables are defined as ratios between sales to the coop and production available for sale (defined as the difference between production and home consumption, including feeding calves). A farmer is defined as present biased if she is more impatient when splitting KSh 200 between today and next week than between next week and the subsequent one. Trust for either the coop and the buyer is measured on an index from 1 to 4 . Therefore, their difference can span -3 to 3. Regular Income from Other Occupation refers to permanent employee, civil servant, artisan, trader, and self-employed. The randomization was stratified by farmer location (i.e., four zones) and baseline delivery levels (i.e., above/below median). We report p-values based on specifications that include stratum fixed effects. ${ }^{*} \mathrm{p}<0.1,{ }^{* *} \mathrm{p}<0.05,{ }^{* * *} \mathrm{p}<0.01$. 


\section{Table C.4: Price and Liquidity Experiment: Heterogeneous Treatment Effects}

\begin{tabular}{|c|c|c|c|}
\hline & $(1)$ & $(2)$ & $(3)$ \\
\hline Post*Bonus $(\gamma)$ & $\begin{array}{l}-0.009 \\
(0.066)\end{array}$ & $\begin{array}{c}0.059 \\
(0.036)\end{array}$ & $\begin{array}{c}0.294 \\
(0.182)\end{array}$ \\
\hline Post*(Bonus+Flexibility) $(\delta)$ & $\begin{array}{c}-0.273 \\
(0.223)\end{array}$ & $\begin{array}{c}0.413^{* *} \\
(0.197)\end{array}$ & $\begin{array}{c}0.046 \\
(0.045)\end{array}$ \\
\hline Post*Bonus*Average Daily Deliveries in Sep 2014 & $\begin{array}{c}0.034 \\
(0.023)\end{array}$ & & \\
\hline Post*(Bonus+Flex)*Average Daily Deliveries in Sep 2014 & $\begin{array}{l}0.128^{*} \\
(0.074)\end{array}$ & & \\
\hline Post*Bonus*Loyalty PM & & $\begin{array}{c}0.093 \\
(0.087)\end{array}$ & \\
\hline Post*(Bonus+Flex)*Loyalty PM & & $\begin{array}{c}-0.314 \\
(0.205)\end{array}$ & \\
\hline Post*Bonus*Any Other Village Trader & & & $\begin{array}{l}-0.235 \\
(0.185)\end{array}$ \\
\hline Post*(Bonus+Flex)*Any Other Village Trader & & & $\begin{array}{l}0.228^{*} \\
(0.121)\end{array}$ \\
\hline$R^{2}$ & 0.087 & 0.051 & 0.043 \\
\hline Dependent Variable Mean & 0.082 & 0.080 & 0.076 \\
\hline Farmer FE & $\mathrm{X}$ & X & $\mathrm{X}$ \\
\hline Farmers & 398 & 378 & 396 \\
\hline Observations & 2388 & 2268 & 2376 \\
\hline
\end{tabular}

Notes: The table presents heterogeneous treatment effects for the Price and Flexibility randomized experiment described in Section 5.2. Farmers in the Bonus group received an increase in milk price of 10 Kenyan shillings for afternoon deliveries. Farmers in the Bonus +Flexibility group received the same price increase and the option to be paid daily. We report results from the difference-in-differences model with farmer FE from Table 3. Column (3). The dependent variable is the kilograms of milk the farmer delivers to the coop in the afternoon. Refer to the notes of Table 3 for further details on the specification. Avg Daily Deliveries are from coop administrative data. Both production and delivery variables are measured in kilograms. Loyalty variables are defined as ratios between afternoon sales to the coop and afternoon production available for sale (defined as the difference between production and home consumption, including feeding calves). Standard errors are clustered at the farmer level. ${ }^{*} \mathrm{p}<0.1,{ }^{*} \mathrm{p}<0.05,{ }^{* * *} \mathrm{p}<0.01$. 